\title{
Solving Portfolio Optimization Problems Using MOEA/D and Lévy Flight
}

\author{
Yifan He, Claus Aranha \\ he.yifan.xs@alumni.tsukuba.ac.jp, caranha@cs.tsukuba.ac.jp \\ The University of Tsukuba
}

March 17, 2020

\begin{abstract}
Portfolio optimization is a financial task which requires the allocation of capital on a set of financial assets to achieve a better tradeoff between return and risk. To solve this problem, recent studies applied multi-objective evolutionary algorithms (MOEAs) for its natural biobjective structure. This paper presents a method injecting a distributionbased mutation method named Lévy Flight into a decomposition based MOEA named MOEA/D. The proposed algorithm is compared with three MOEA/D-like algorithms, NSGA-II, and other distribution-based mutation methods on five portfolio optimization benchmarks sized from 31 to 225 in OR library without constraints, assessing with six metrics. Numerical results and statistical test indicate that this method can outperform comparison methods in most cases. We analyze how Lévy Flight contributes to this improvement by promoting global search early in the optimization. We explain this improvement by considering the interaction between mutation method and the property of the problem.
\end{abstract}

\section{Introduction}

Multi-Objective Optimization Problems (MOOP) consist of several conflicting objectives and require that an optimization algorithm finds an optimal set of trade-offs rather than a single optimal solution. In the financial world, researchers and investors face a famous MOOP known as portfolio optimization (PO). The goal of this problem is to find an optimal allocation of capital among a finite set of available financial assets, by maximizing portfolio return and minimizing portfolio risk simultaneously. One of the challenges of this problem comes from its complex and large search space. Although the unconstrained model of modern portfolio theory contributed by Markowitz Markowitz, 1952] states that $\mathrm{PO}$ can be solved using a quadratic programming method, realistic constraints make the problem NP-hard Bienstock, 1996]. 


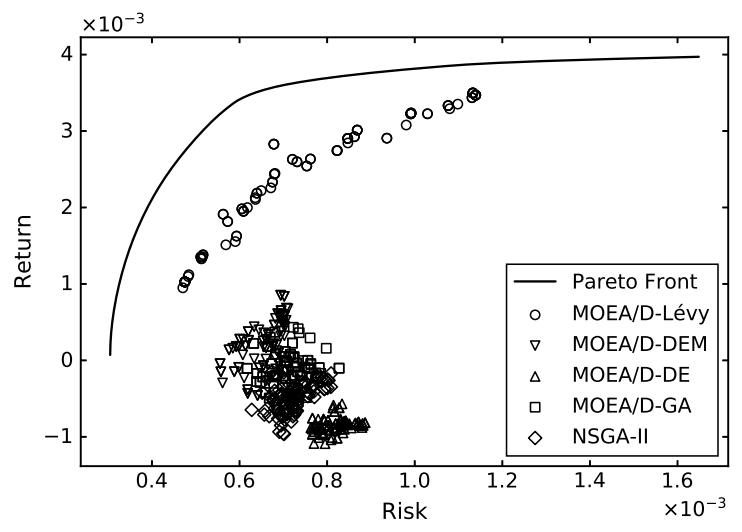

Figure 1: Population of different methods for the Nikkei dataset at the 10th generation. The proposed method (MOEA/D-Lévy) quickly explores a larger area of the objective space.

To solve this complex problem, evolutionary algorithms (EAs) are frequently applied. By assigning different weights to each objective, the PO can be addressed in a single-objective form. However, considering its natural bi-objective formulation, researchers have paid increasing efforts on methods using multiobjective evolutionary algorithms (MOEAs). Some domination-based MOEAs, such as MOGA, PAES, SPEA2 and NSGA-II, have been assessed on PO benchmarks Skolpadungket et al., 2007; Mishra et al., 2009a, 2011; Anagnostopoulos and Mamanis, 2011b, or applied on practical PO applications Duran et al., 2009; Anagnostopoulos and Mamanis, 2011a]. Also, several multi-objective variants of swarm intelligence methods, namely non-dominated sorting Multi-Objective Particle Swarm Optimization (NS-MOPSO) [Mishra et al., 2014a], Multi-Objective Bacteria Foraging Optimization (MOBFO) Mishra et al., 2014b|, and Multi-objective Co-variance based Artificial Bee Colony (M-CABC) [Kumar and Mishra, 2017], have been introduced to the PO literature in the recent years. However, only a few PO researchers have paid attention to MOEA based on Decomposition (MOEA/D) Zhang et al., 2010, 2018; Zhou et al., 2018]. This powerful decomposition-based MOEA has not been well-discussed on $\mathrm{PO}$ yet.

Recently, researchers have paid attention to Lévy Flight (LF) for solving hard optimization problems. Prior studies have shown the strong search capability of this mutation method Viswanathan et al., 2008; Hakl and Uuz, 2014]. In this paper, we propose a method named MOEA/D-Lévy, which injects LF into MOEA/D, and assess it on PO with unit constraint (Section 3). This modification is motivated by the efficient global search performance of LF. As one of the main challenges in the PO is the high-dimensionality of the search space, we expect the global search capability of LF can overcome this difficulty during optimization. Our experiments (Section 4) include a comparison 
with literature methods and a comparison with mutations based on different probability distributions. The results of six evaluation metrics, as well as a statistical test on all five datasets in a frequently used PO benchmark in OR Library [Chang et al., 2000], indicate that this method outperforms the comparison methods in most cases. Additionally, we use an experiment to show how the addition of LF contributes to the optimization process (Section 5). Fig. 1 illustrates this contribution, by showing the population of five methods on the objective space at the 10-th generation when optimizing for the Nikkei dataset. It is interesting to notice that at the very beginning of optimization the proposed method, represented by circles, can achieve a relatively good solution set compared to other literature methods. We suggest this may be caused by a compound factor of LF and the repair method, as well as the characteristics of the PO problem. To our best knowledge, no research has applied LF into MOEA/D in the PO literature. The code and data used for the experiments in this paper are available at a public repository1.

\section{Background}

\subsection{Portfolio Optimization}

PO requires an allocation of capital among a set of available financial assets to achieve a better trade-off between return and risk. Fig. 2 provides an example of a portfolio on four stocks. The whole pie represents all capital and the rate in the sectors represents invest rate on the corresponding assets (e.g. $30 \%$ of the capital has been allocated into Google stock). The initial work by Markowitz Markowitz, 1952] models PO as the following bi-objective formulation. In this PO model, the first objective (return) is being maximized, while the second objective (risk) is being minimized. This model requires to allocate

all of the capital during the investment. This is usually represented as the sum of investments being equal to one (unit constraint). $\boldsymbol{w}=\left(w_{1}, w_{2}, \ldots, w_{n}\right)$ is a vector representing the invest ratios of $n$ assets. $r_{i}$ is the return rate of $i$-th asset, and $\sigma_{i j}$ is co-variance between the return rated of $i$-th asset and $j$-th asset.

$$
\begin{gathered}
\max _{\boldsymbol{w}} R E T U R N=\sum_{i=1}^{n} r_{i} w_{i} \\
\min _{\boldsymbol{w}} R I S K=\sum_{i=1}^{n} \sum_{j=1}^{n} \sigma_{i j} w_{i} w_{j}
\end{gathered}
$$

subject to,

$$
\sum_{i=1}^{n} w_{i}=1,\left(0 \leq w_{i} \leq 1\right)
$$

\footnotetext{
${ }^{1}$ https://github.com/Y1fanHE/po_with_moead-levy
} 


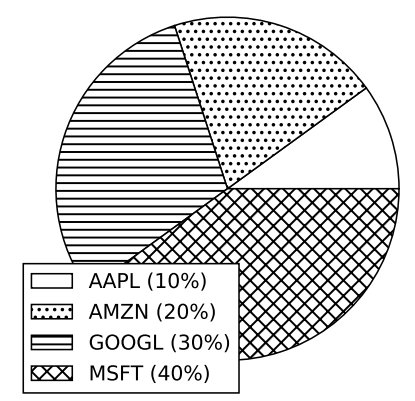

Figure 2: A sample portfolio on four assets

It is easy to notice that PO belongs to the big category of multi-objective optimization problems (MOOPs). MOOP is a class of optimization problems which contain more than one conflicting objectives. Compared to single-objective optimization problems (SOOPs), MOOPs aim to achieve an optimal set of solution showing best trade-off between its multiple objectives rather than one single optimal solution. Such an optimal set named Pareto Front contains all the feasible solutions that are not dominated by any other solutions in problem feasible region.

\subsection{Multi-Objective Evolutionary Algorithms}

There is a large number of MOEAs. Many MOEAs, such as NSGA-II Deb et al., 2002], find a set of trade-off solutions using the concept of domination, where two solutions are non-dominates if each solution has at least one objective where it is better than the other one. As an alternative approach, MOEA/D Qingfu Zhang and Hui Li, 2007] achieves Pareto Front by decomposing a MOOP into several single objective optimization problems (SOOP), and optimizing them simultaneously. One of the most frequently used decomposition methods is Tchebycheff approach. This approach transfers vector optimization into scalar optimization with a weight vector $\boldsymbol{\lambda}$ and a reference point $\boldsymbol{z}^{*}$ as follows (i.e.,minimization example), where $z_{m}^{*}$ is the minimum value of $m$-th objective. By using this method, the retrieved optimal is the intersection of Pareto Front and the straight line determined by $\boldsymbol{\lambda}$ and $\boldsymbol{z}^{*}$.

$$
\begin{gathered}
\min _{\boldsymbol{x}} g^{t e}\left(\boldsymbol{x} \mid \boldsymbol{\lambda}, \boldsymbol{z}^{*}\right)=\max _{m=1, \ldots, M}\left\{\lambda_{m}\left|f_{m}(\boldsymbol{x})-z_{m}^{*}\right|\right\} \\
\boldsymbol{\lambda}=\left(\lambda_{1}, \ldots, \lambda_{M}\right), \lambda_{1}+\ldots+\lambda_{M}=1 \\
\boldsymbol{z}^{*}=\left(\min f_{1}, \ldots, \min f_{M}\right)
\end{gathered}
$$




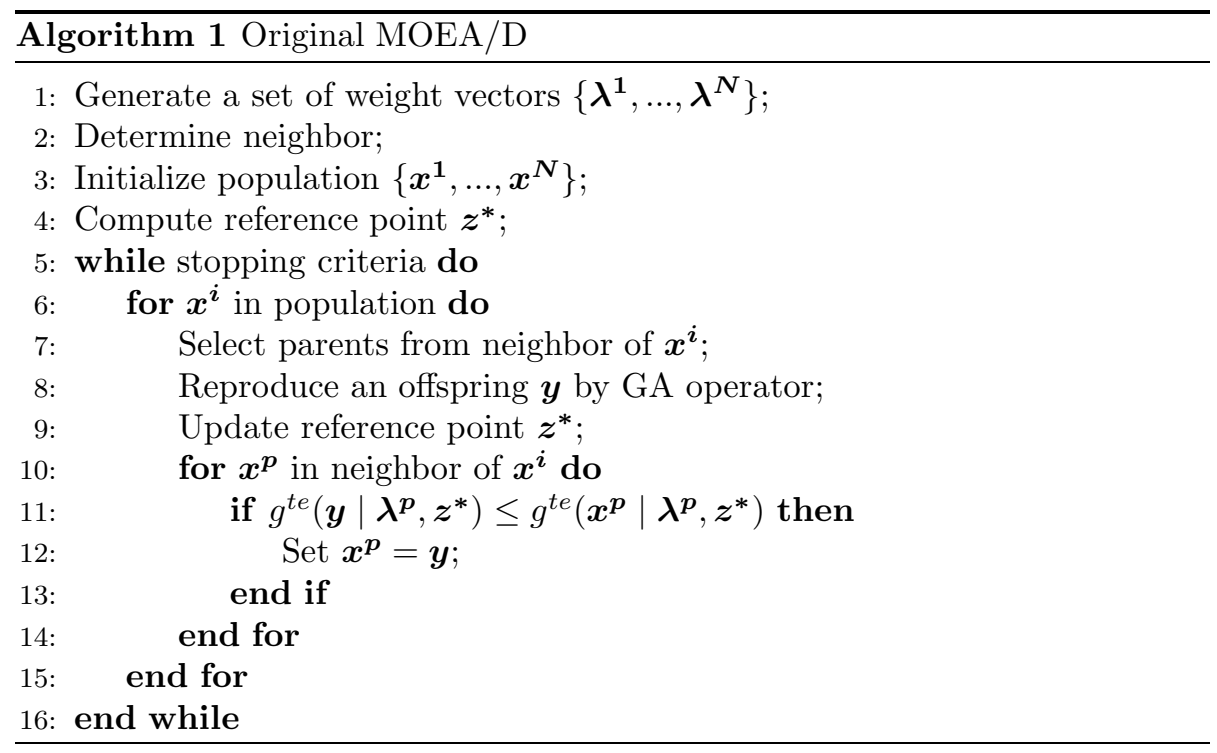

In MOEA/D, every individual in the population is optimized as the solution of one SOOP decomposed using one weight vector. During optimization, the solution uses the information of its neighbor. The neighbor is defined as solutions of neighboring SOOPs, which can be computed using the closest Euclidean distance between weight vectors. When reproducing an offspring, MOEA/D selects parents from the neighbors of the current individual. Once the offspring are generated, it can be used to update all neighbors of the current individual. Algorithm 1 1 shows a detailed description of MOEA/D.

Recently, researchers have tried to combine MOEA/D with mutation methods in other meta-heuristics to enhance its search capability, such as Particle Swarm Optimization (PSO), Differential Evolution (DE), and Ant Colony Optimization (ACO) Wei Peng and Zhang, 2008; Hui Li and Qingfu Zhang, 2009; Ke et al., 2013]. MOEA/D-DE [Hui Li and Qingfu Zhang, 2009] injects the DE operator and polynomial mutation operator into MOEA/D. The DE operator is present as follows, where $\boldsymbol{x}^{i}, \boldsymbol{x}^{\boldsymbol{j}}$ and $\boldsymbol{x}^{\boldsymbol{k}}$ are parents, $\boldsymbol{y}$ is offspring, and rand is a random number between 0 and 1 .

$$
\boldsymbol{y}= \begin{cases}\boldsymbol{x}^{\boldsymbol{i}}+F \cdot\left(\boldsymbol{x}^{\boldsymbol{j}}-\boldsymbol{x}^{\boldsymbol{k}}\right), & \text { rand }<C R \\ \boldsymbol{x}^{i}, & \text { rand } \geq C R\end{cases}
$$

The original DE operator includes a DE mutation step and a crossover step with the original parent. However, the authors of MOEA/D-DE have suggested setting $C R$ to 1.0 to deal with complicated problems, which means only the DE mutation step will be implemented. Additionally, they have designed a diversity keeping strategy, including an upper limitation for updating neighbor, and a small probability to select parents from the whole population rather than the neighbor. The parent selection scheme of MOEA/D-DE has been well discussed 
by Tanabe Tanabe and Ishibuchi, 2019]. This study has reported that using curr/1 (i.e., select current individual as $\boldsymbol{x}^{i}$ ) and WR (i.e., $\boldsymbol{x}^{i}, \boldsymbol{x}^{j}, \boldsymbol{x}^{k}$ can be the same individual) or WPR (i.e., $\boldsymbol{x}^{j}$ and $\boldsymbol{x}^{\boldsymbol{k}}$ cannot be same, but either can be the same as $\boldsymbol{x}^{i}$ ) outperforms other settings.

\subsection{Portfolio Optimization Using MOEAs}

Since the genetic algorithm was firstly introduced into PO literature in a multiobjective form in 1993 [Arnone et al., 1993], prior studies have assessed a large group of MOEAs. One frequently used benchmark in these assessments is the OR library [Chang et al., 2000], which contains five PO datasets, namely Hangseng, DAX 100, FTSE 100, S\&P 100 and Nikkei. VEGA, Fuzzy VEGA, MOGA, SPEA2, and NSGA-II have been compared on Hangseng with constraints [Skolpadungket et al., 2007]. Another two comparison studies using the same dataset have reported that NSGA-II outperforms PESA, PAES and APAES Mishra et al., 2009a, 2011. NSGA-II, PESA, and SPEA2 have also been assessed on DAX 100 with constraints Anagnostopoulos and Mamanis, 2011b. The results have shown that NSGA-II and SPEA2 hold the best average performance. In Brankes study Branke et al., 2009], envelope-based MOEA has been assessed on Hangseng, S\&P 100, and Nikkei with realistic constraints.

While EAs are modeled from the evolutionary process, swarm intelligence (SI) is a group of algorithms based on the self-organization of individuals. A survey has reported increasing attention on using MOEAs with SI to solve PO [Ertenlice and Kalavci, 2018]. MOPSO has been compared with PSFGA, SPEA2, and NSGA-II on Hangseng [Mishra et al., 2009b]. The results have indicated that MOPSO outperforms the other three methods significantly. NSMOPSO, MOBFO, and M-CABC have been proposed and assessed on all five PO datasets in the OR library with constraints Mishra et al., 2014a, b; Kumar and Mishra, 2017.

Despite performance assessment using benchmarks, researchers have also shown strong interest in developing MOEAs for practical PO. NSGA-II, SPEA2, and IBEA have been compared on solving PO with financial data in the Venezuelan market Duran et al., 2009]. Five domination based MOEAs have been tested on cardinality constrained PO with a dataset containing over 2000 assets Anagnostopoulos and Mamanis, 2011a]. Variants of MOPSO have been proposed to solve the constrained PO with realistic dataset Liang and Qu, 2013; Jianli Zhou and Jun Li, 2014]. Several studies have focused on designing specific initialization methods, problem guided mutation and constraint handling techniques on PO Orito et al., 2013; Liagkouras and Metaxiotis, 2014; Meghwani and Thakur, 2018; Liagkouras and Metaxiotis, 2018].

While most of the prior studies are based on domination methods, few researchers have focused on solving PO with decomposition-based MOEAs. Zhangs study Zhang et al., 2010] has proposed a new decomposition method and used MOEA/D-DE to solve a constrained PO. The experimental results show that MOEA/D-DE performs better than NSGA-II-DE. A new weight vector generation approach to achieve an evenly distributed vector set has been 
proposed by Zhang Zhang et al., 2018]. In Zhous study Zhou et al., 2018], researchers have combined data envelopment analysis techniques with MOEA/D and assessed this method on ZDT1-3 benchmarks as well as PO application on 10 stocks. The results show that the proposed method can outperform MOEA/D. Thus, performance assessment and application of MOEA/D on PO have not been well discussed so far.

In Zhangs study [Zhang et al., 2010], researchers have reported that original Tchebycheff decomposition cannot achieve an evenly distributed optimal set, for the scale of two objectives are usually different in PO. To solve this problem, they have proposed the NBI-style Tchebycheff decomposition approach (i.e., NBI: Normal Boundary Intersection). This approach transfers vector optimization into scalar optimizations with a normal vector $\boldsymbol{\lambda}$ of convex hull of minima (CHIM) and evenly distributed reference points $\left\{\boldsymbol{r}^{\mathbf{1}}, \ldots, \boldsymbol{r}^{\boldsymbol{N}}\right\}$ on CHIM as follows (i.e., bi-objective minimization example), where $\boldsymbol{F}^{\mathbf{1}}$ and $\boldsymbol{F}^{\mathbf{2}}$ are extreme points. By using this method, the $i$-th optimal is the intersection of Pareto Front and the normal line of determined by $\boldsymbol{\lambda}$ and $\boldsymbol{r}^{i}$. In the case of bi-objective optimization problems, CHIM is the straight line between extreme points.

$$
\begin{gathered}
\min _{\boldsymbol{x}} g^{t n}(\boldsymbol{x} \mid \boldsymbol{\lambda}, \boldsymbol{r})=\max _{m=1,2}\left\{\lambda_{m}\left(f_{m}(\boldsymbol{x})-r_{m}\right)\right\} \\
\boldsymbol{\lambda}=\left(\lambda_{1}, \lambda_{2}\right), \lambda_{1}=\left|F_{2}^{2}-F_{2}^{1}\right|, \lambda_{2}=\left|F_{1}^{2}-F_{1}^{1}\right| \\
\boldsymbol{r}^{\boldsymbol{i}}=a_{i} \cdot \boldsymbol{F}^{\mathbf{1}}+\left(1-a_{i}\right) \cdot \boldsymbol{F}^{\mathbf{2}}, a_{i}=\frac{N-i}{N-i}
\end{gathered}
$$

To generate an offspring, they have used DE mutation operator. In that work, the three parents are randomly selected from neighbor of current individual. What is more, although original MOEA/D-DE Hui Li and Qingfu Zhang, 2009] uses diversity keeping strategies, the usage of such strategies has not been reported in Zhang's study.

\subsection{Lévy Flight and Optimization}

Lévy Flight (LF) is a special random walk where step length is drawn from a Lévy-stable distribution (a heavy-tailed distribution). Thus, LF is a process mixing short motions and long trajectories. This property helps escape from local optimal, and thus improves the performance in an optimization task. Fig. 3 shows a comparison of a 100-step random walk in two-dimensional space using a standard normal distribution and Cauchy distribution (i.e., an example of heavytail distribution). The search area of the random walk using Cauchy distribution is much larger than the random walk using the standard normal distribution. One biological application of LF is the LF foraging theory Viswanathan et al., 2008]. This theory states that creatures have evolved to use LF during foraging for its optimized random search capability. Despite this natural example, LF has been applied in optimization problems in various areas such as physics, biology, statistics, finance, and economics [Kamaruzaman et al., 2013]. 


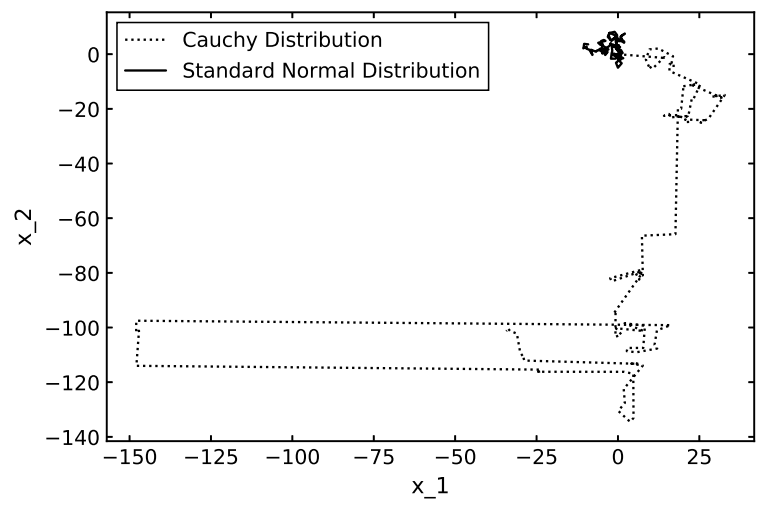

Figure 3: A comparison on random walks using the normal distribution and the Cauchy distribution (Lévy Flight). Using occasional long jumps, LF explores a larger area than the Normal random walk.

In addition, researchers have developed and enhanced metaheuristics using LF. Cuckoo Search (CS) Yang and Suash Deb, 2009] is an efficient optimization method using LF to implement a global search. Researchers have also used LF to enhance PSO and ABC Hakl and Uuz, 2014; Ma et al., 2015; Jensi and Jiji, 2016; Aydogdu et al., 2016]. In Zhang's study Zhang et al., 2019], a modified CS has been injected into MOEA/D to solve a spectrum allocation problem. However, the mis-setting of evaluation times (i.e., they do not set an equal evaluation time for all algorithms in the experiment) and the unclear algorithm description (i.e., they do not report some details in the numerical process when describing algorithm procedure) may confuse other researchers when understanding and implementing this method. Thus, there remains a proper assessment of MOEA/D injected with LF. Some studies have applied the single-objective form of CS to solve PO Shadkam et al., 2015; Faezy Razi and Shadloo, 2016; El-Bizri and Mansour, 2017]. However, to our best knowledge, there is no research injecting LF into MOEA/D in the PO literature.

Cauchy distribution is one of the stable distributions. Thus, Cauchy mutation can be seen as a special case of LF. Prior studies have shown the superiority of Cauchy mutation in diversity keeping. Ali has proposed a hybrid method based on DE and Cauchy mutation. [Ali and Pant, 2011] Ali's algorithm performs Cauchy mutation on the best individual when DE mutation fails to update in several continuous generations. This modification is proved to be efficient to avoid the premature issue of DE in their experiments. However, this algorithm does not take Cauchy mutation as the main method. Several works have designed adaptive strategies for DE based on Cauchy distribution Choi et al., 2013; Zhang and Sanderson, 2009]. These algorithms generate parameters from the Cauchy distribution and update the expectation value of Cauchy distribu- 
tion based on successfully updates solutions.

\section{Proposed Method}

\subsection{Lévy Flight Mutation}

The LF mutation in the proposed method is similar to the DE mutation, utilizing the difference between individuals. However, the scaling factor in LF mutation is a vector generated from heavy-tail distribution rather than a constant. What is more, LF mutation only uses two parents, while DE mutation uses three parents. The formulation of this mutation method is as follows, where $\boldsymbol{x}^{\boldsymbol{i}}$ and $\boldsymbol{x}^{\boldsymbol{j}}$ are parents, $\boldsymbol{y}$ is offspring, $\oplus$ means entry-wise multiplication, $\alpha_{0}$ is a scaling factor, and $\boldsymbol{L} \operatorname{é} \boldsymbol{v y}(\boldsymbol{\beta})$ is a vector where each component is generated using Mantegnas algorithm (MA) Mantegna and Stanley, 1994 (i.e., $0.3 \leq \beta \leq 1.99$ ). This algorithm generates random numbers from symmetric Lévy-stable distribution. MA is present following LF mutation, where $\Gamma$ represents the Gamma function.

$$
\begin{gathered}
\boldsymbol{y}=\boldsymbol{x}^{\boldsymbol{i}}+\alpha_{0} \cdot\left(\boldsymbol{x}^{\boldsymbol{i}}-\boldsymbol{x}^{\boldsymbol{j}}\right) \oplus \boldsymbol{L} \dot{\boldsymbol{e}} \boldsymbol{v} \boldsymbol{y}(\boldsymbol{\beta}) \\
\boldsymbol{L} \dot{\boldsymbol{v}} \boldsymbol{y}(\boldsymbol{\beta}) \sim \frac{\boldsymbol{u}}{|\boldsymbol{v}|^{1 / \beta}}, \boldsymbol{u} \sim \boldsymbol{N}\left(0, \sigma_{u}^{2}\right), \boldsymbol{v} \sim \boldsymbol{N}\left(0, \sigma_{v}^{2}\right) \\
\sigma_{u}=\left\{\frac{\Gamma(1+\beta) \sin (\pi \beta / 2)}{\Gamma[(1+\beta) / 2] \beta 2^{(\beta-1) / 2}}\right\}^{1 / \beta}, \sigma_{v}=1
\end{gathered}
$$

$\beta$ is the stability parameter controlling the shape of a stable distribution, and thus can control the balance between local and global search in LF. A smaller $\beta$ holds a stronger global search capability. When $\beta$ is set to 1 , MA generates Cauchy random numbers. However, there are several differences between our LF mutation and Cauchy mutation that mentioned in the previous section. First, compared with Ali's work Ali and Pant, 2011], our method applies LF mutation in all generations. Second, compared with adaptive strategies based on Cauchy distribution Choi et al., 2013; Zhang and Sanderson, 2009], our mutation method performs entry-wise multiplication, while the adaptive strategy only generates constant scaling factors, and our method is not an adaptive strategy. Third, in our later experiment, we use $\beta=0.3$ rather than 1 . Thus, we actually are not using Cauchy mutation but a more general method. What is more, this mutation method not only does a diversification but also utilizes the property of the PO problem (we show this in the later experiments).

\subsection{Repair Method}

The offspring generated by LF mutation may not satisfy the unit constraint in (3). Thus, it is necessary to apply a proper constraint handling technique after reproduction. In this research, a general repair method following the description in Algorithm 2 has been applied. These repair steps will first set negative variables to 0 , and then scale the entire vector (offspring) so that the summation of all variables equals to 1 . 


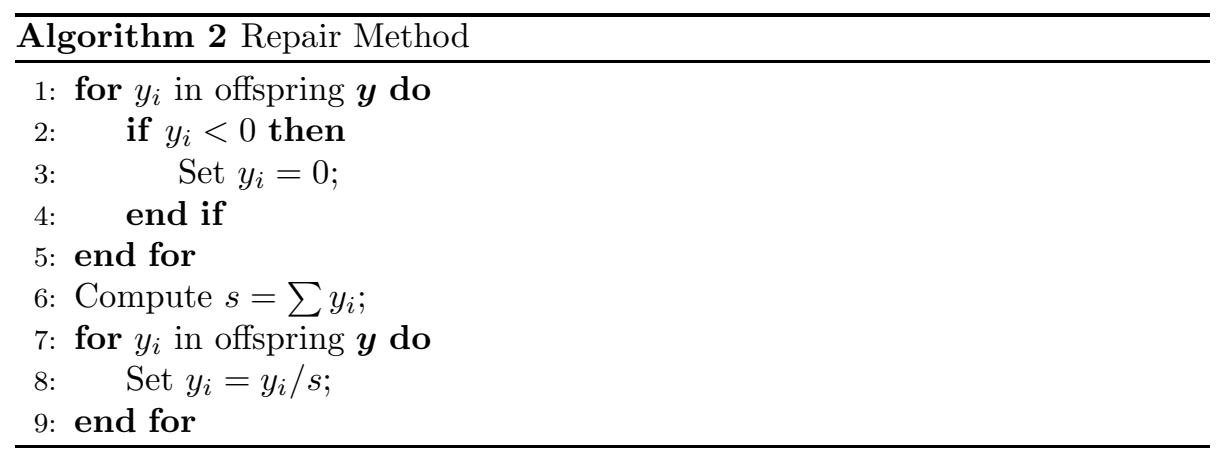

\subsection{Proposed MOEA/D-Lévy Algorithm}

An entire algorithmic description of the proposed method is presented in Algorithm 3 . In the following sections, the proposed method will be named as MOEA/D-Lévy for convenience. As our problem only includes unit constraint, the representation of a portfolio in our algorithm is a vector, where each component is an invest rate of one asset. In MOEA/D-Lévy, each variable of a solution is initialized using a uniform distribution between 0 and 1 . When selecting parents, the current individual is selected as $\boldsymbol{x}^{i}$, while $\boldsymbol{x}^{j}$ is randomly selected from the neighbors of the current individual. MOEA/D-Lévy injects LF mutation and polynomial mutation operators into MOEA/D. When an offspring is generated, the algorithm will implement repair steps to satisfy constraints in (3). NBI-style Tchebycheff decomposition approach (i.e., described in Section 2.3 has been applied to deal with different scales of two objectives in PO. We have also applied the diversity keeping strategies proposed in Lis study Hui Li and Qingfu Zhang, 2009] (i.e., described in Section [2.2), including a small proportion $1-\sigma$ to select parents from the whole population (i.e., described in Algorithm [3, Line 6 to 10), where $\operatorname{rand}(0,1)$ means a random number generated from uniform distribution with range 0 to 1 , as well as an upper limitation $n_{r}$ for updating neighbor (i.e., described in Algorithm 3 , Line 20 to 23). The normal vector $\boldsymbol{\lambda}$ and reference point $\boldsymbol{r}^{\boldsymbol{p}}$ are computed based on (9) and (10).

Compared with the original MOEA/D algorithm Qingfu Zhang and Hui Li, 2007], the main modification of MOEA/D-Lévy includes NBI-style Tchebycheff decomposition (the original MOEA/D applies Tchebycheff method), diversity keeping strategies (the original MOEA/D does not apply it), and reproduction method based on LF and polynomial mutation (the original MOEA/D applies GA operator). 


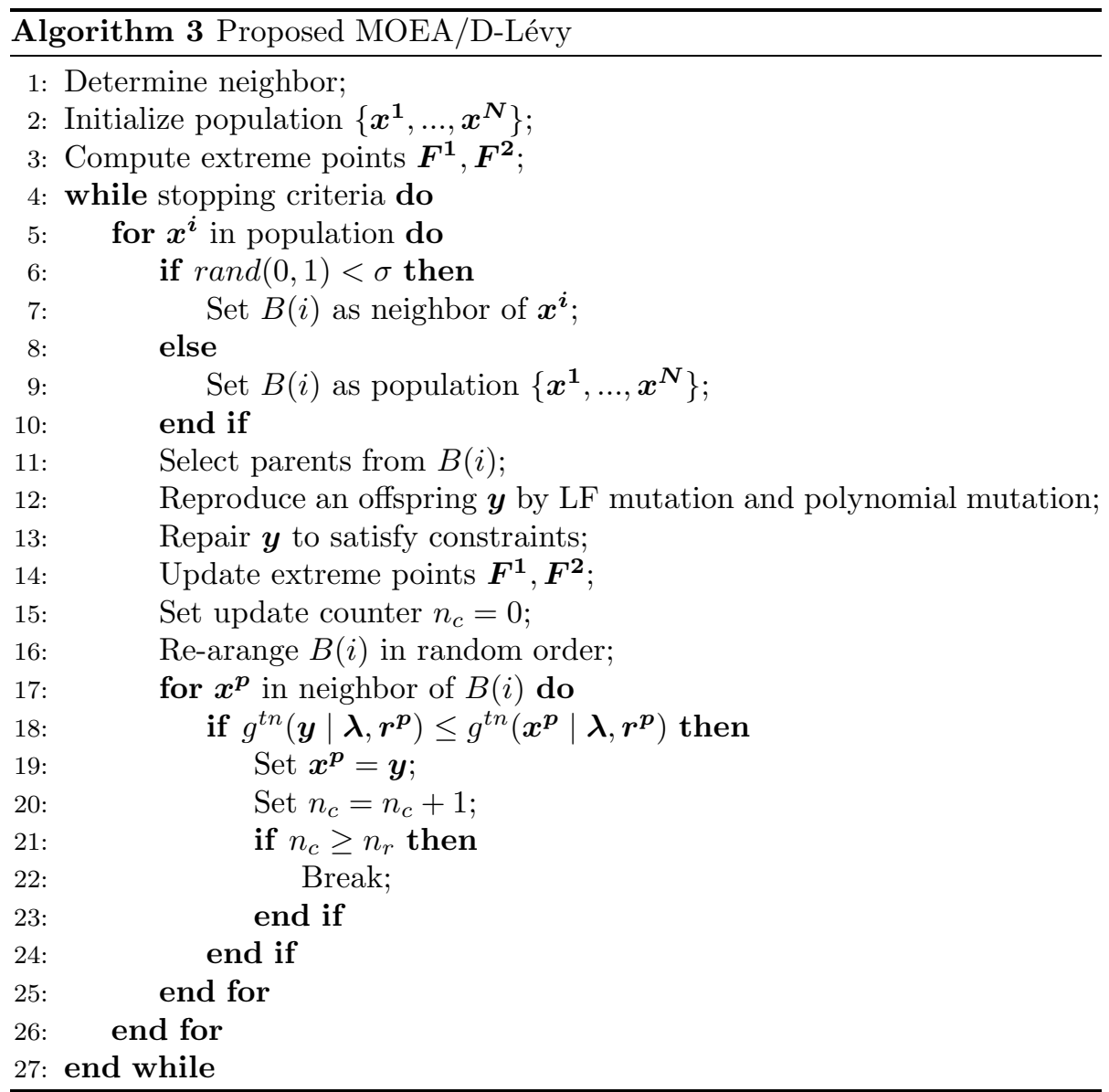

\section{Experiments}

\subsection{Experimental Method}

In this study, the goal is to assess the performance of LF as a mutation method in MOEA/D. Therefore, in Experiment I we compare MOEA/D-Lévy with three variants of MOEA/D and NSGA-II. In addition, to show the effectiveness of LF, in Experiment II we compare variants of the proposed algorithm using different distributions. The benchmarks used are all five PO datasets in the OR library [Chang et al., 2000], containing 31, 85, 89, 98, and 225 assets from 1992 to 1997 , respectively. A summary of the datasets is presented in Table 1.

When evaluating MOEAs, it is important to consider both convergence and diversity performance. Although there are several metrics assessing convergence, such as generation distance (GD), and diversity, such as spacing (S), maximum spread (MS), spread $(\Delta)$, a recent trend in the literature is to assess the two performance at one time using overall metrics, such as inverted generation dis- 
tance (IGD) and hypervolume (HV). In this study, all six metrics (i.e., GD, S, MS, $\Delta$, IGD and HV) are applied. The calculation methods of GD, S, MS, $\Delta$ and HV are referred to Chapter 8 in Debs book [Deb, 2001]. For IGD, we refer to Coellos study [Coello Coello and Reves Sierra, 2004] which first proposed the IGD metric. A smaller value in GD, S, $\Delta$ and IGD indicates better performance, while for MS and $\mathrm{HV}$, a larger value represents better performance.

- GD: $d\left(\boldsymbol{v}, P^{*}\right)$ is the minimum Euclidean distance between a non-dominated solution $\boldsymbol{v}$ and Pareto Front $P^{*}$.

$$
\frac{\sum_{\boldsymbol{v} \in A} d\left(\boldsymbol{v}, P^{*}\right)}{|A|}
$$

- $\mathbf{S}: d_{i}$ is the minimum Manhattan distance between $i$-th non-dominated solution and another one.

$$
\sqrt{\frac{1}{N^{\prime}} \sum_{i=1}^{N^{\prime}}\left(\bar{d}-d_{i}\right)^{2}}
$$

- MS: $f_{m}^{i}$ is the $m$-th objective of $i$-th non-dominated solution.

$$
\sqrt{\sum_{m=1}^{M}\left(\max _{i=1, \ldots, N^{\prime}} f_{m}^{i}-\min _{i=1, \ldots, N^{\prime}} f_{m}^{i}\right)^{2}}
$$

- $\Delta: d_{i}$ is the Euclidean distance between two consecutive non-dominated solutions; $d_{f}$ and $d_{l}$ are the Euclidean distance between extreme solutions of Pareto Front and boundary solutions of non-dominated set.

$$
\frac{d_{f}+d_{l}+\sum_{i=1}^{N^{\prime}-1}\left|d_{i}-\bar{d}\right|}{d_{f}+d_{l}+\left(N^{\prime}-1\right) \bar{d}}
$$

- IGD: $d(\boldsymbol{v}, A)$ is the minimum Euclidean distance between a solution $\boldsymbol{v}$ in Pareto Front $P^{*}$ and non-dominated set $A$.

$$
\frac{\sum_{\boldsymbol{v} \in P^{*}} d(\boldsymbol{v}, A)}{\left|P^{*}\right|}
$$

- HV: $v_{i}$ is the hypercube constructed with a reference point and $i$-th nondominated solution as the diagonal corners. To compute the reference point, the Nadir point of solutions generated by all algorithms in the final generation will be used.

$$
\text { volume }\left(\bigcup_{i=1}^{N^{\prime}} v_{i}\right)
$$


Table 1: A summary of the datasets used in experiments

\begin{tabular}{cccc}
\hline Dataset & Region & Size & Time Period \\
\hline Hangseng & Hongkong & 31 & \\
DAX 100 & Germany & 85 & \\
FTSE 100 & U.K. & 89 & $1992 \sim 1997$ \\
S\&P 100 & U.S. & 98 & \\
Nikkei & Japan & 225 & \\
\hline
\end{tabular}

Table 2: A summary of mutation methods in Experiment I

\begin{tabular}{cc}
\hline Method & Mutation Formula \\
\hline MOEA/D-Lévy & $\boldsymbol{y}=\boldsymbol{x}^{\boldsymbol{i}}+\alpha_{0} \cdot\left(\boldsymbol{x}^{\boldsymbol{i}}-\boldsymbol{x}^{\boldsymbol{j}}\right) \oplus \boldsymbol{L e ́} \boldsymbol{v} \boldsymbol{y}(\boldsymbol{\beta})$ \\
& polynomial mutation \\
& $\boldsymbol{y}=\boldsymbol{x}^{\boldsymbol{i}}+F \cdot\left(\boldsymbol{x}^{\boldsymbol{j}}-\boldsymbol{x}^{\boldsymbol{k}}\right)$ \\
MOEA/D-DEM & polynomial mutation \\
MOEA/D-DE & $\boldsymbol{y}=\boldsymbol{x}^{\boldsymbol{i}}+F \cdot\left(\boldsymbol{x}^{\boldsymbol{j}}-\boldsymbol{x}^{\boldsymbol{k}}\right)$ \\
MOEA/D-GA & SBX crossover and \\
NSGA-II & polynomial mutation \\
\hline
\end{tabular}

Both experiments are implemented with 51 repetitions. For every single run, the values of the six metrics at the final generation are calculated. All five datasets share the same parameter setting. The parameters are set as follows. For all methods, population size and maximum generation are set to 100 and 1500. An early stop criterion (convergence) is set when the variation of IGD is not larger than 1e-05 for 100 continuous generations. Neighbor size $T$, proportion $\sigma$ to select parents from the neighbors and upper limitation $n_{r}$ for updating neighbors in MOEA/D-based methods are set to 20, 0.9 and 2. These settings (i.e., $T, \sigma$ and $n_{r}$ ) are the same as Lis study Hui Li and Qingfu Zhang, 2009].

The parameter settings of the mutation methods that differentiate the compared algorithms will be presented in Section 4.2 and Section 4.3 . These parameters are fine-tuned by a pre-experiment, using the Nikkei dataset. We perform 30 runs, stopping at the 300-th generation, and choose the parameters that receive the best average IGD to be used in the formal experiments. Fig. 4 shows an example for $\beta$ parameter tuning on the proposed algorithm.

Table 3: A summary of mutation methods in Experiment II

\begin{tabular}{|c|c|}
\hline Method & Mutation Formula \\
\hline LEVY & $\bar{y}=\boldsymbol{x}^{\boldsymbol{i}}+\alpha_{0} \cdot\left(\boldsymbol{x}^{\boldsymbol{i}}-\boldsymbol{x}^{\boldsymbol{j}}\right) \oplus \boldsymbol{L}$ évy $(\boldsymbol{\beta})$ \\
\hline UNIF & $y=x^{i}+C \cdot\left(x^{j}-x^{k}\right) \oplus \operatorname{Unif}(-1,1)$ \\
\hline NORM & $y=x^{i}+C \cdot\left(x^{j}-x^{k}\right) \oplus N(\mathbf{0}, \mathbf{1})$ \\
\hline CONST & $y=x^{i}+F \cdot\left(x^{j}-x^{k}\right)$ \\
\hline
\end{tabular}


Table 4: Reference points used on five datasets

\begin{tabular}{cc}
\hline Dataset & Reference Point (return, risk) \\
\hline Hangseng & $(0.0026,0.0048)$ \\
DAX 100 & $(0.0019,0.0028)$ \\
FTSE 100 & $(0.0024,0.0028)$ \\
S\&P 100 & $(0.0018,0.0031)$ \\
Nikkei & $(-0.0026,0.0017)$ \\
\hline
\end{tabular}

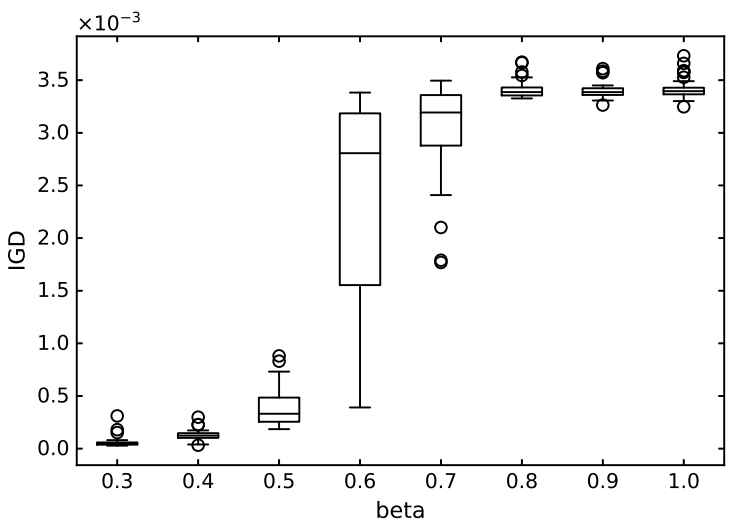

Figure 4: An example of parameter tuning on MOEA/D-Lévy

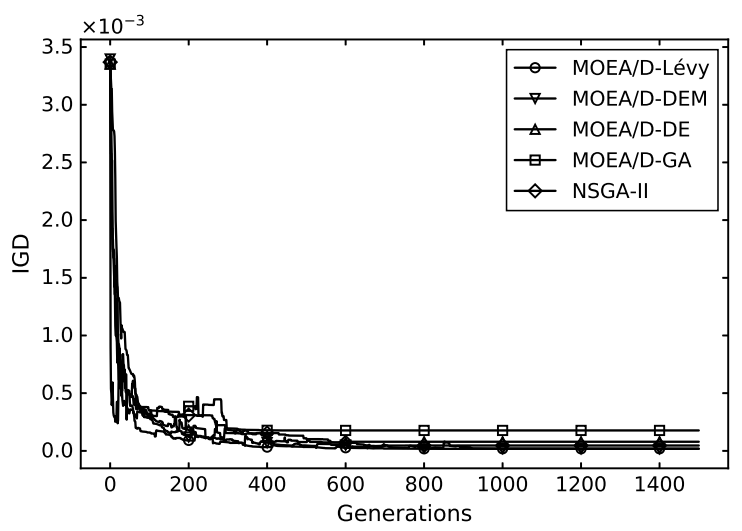

Figure 5: IGD by generations on Nikkei in Experiment I 


\subsection{Experiment I: Comparison with Literature Methods}

In this experiment, MOEA/D-Lévy and four comparison methods, MOEA/DDEM, MOEA/D-DE, MOEA/D-GA and NSGA-II, are included. Among these five methods, four are based on MOEA/D framework described in Lis study Hui Li and Qingfu Zhang, 2009] (i.e., a small proportion to select parents from the whole population and an upper limitation for updating neighbors are set), while the decomposition method applied is NBI-style Tchebycheff approach [Zhang et al., 2010]. The selection method of all methods except the two GA-based algorithms is to select the current visited individual as one of the parents, and to randomly select the other individual as the other parents (i.e., same as Lis study Hui Li and Qingfu Zhang, 2009]). For MOEA/D-GA, all the parents are randomly selected from neighbors or the whole population, and a binary tournament selection is applied in NSGA-II. The mutation method in MOEA/D-Lévy has been described in Line 12, Algorithm 3. In MOEA/D-DEM, the mutation is the same as Lis study [Hui Li and Qingfu Zhang, 2009] (i.e., DE mutation and polynomial mutation). In MOEA/D-DE, the mutation method is only based on DE mutation. This setting is applied in Zhangs study [Zhang et al., 2010]. For two GA-based algorithms, SBX crossover and polynomial mutation are applied. This setting is the same as original NSGA-II Deb et al.,2002] and MOEA/D Qingfu Zhang and Hui Li, 2007] algorithms. In Table 2, detailed mutation methods in Experiment I are listed.

Following the pre-experimental tuning described in Section 4.1 we obtained the following parameter values. In MOEA/D-Lévy, $\alpha_{0}$ and $\beta$ of LF mutation are set to 1e-05 and 0.3. In MOEA/D-DEM and MOEA/D-DE, scaling factor $F$ of DE mutation is set to 1.3. In MOEA/D-Lévy and MOEA/D-DEM, mutation rate is set to $1 / n$ (i.e., $n$ is the size of dataset). In MOEA/D-GA and NSGA-II, crossover rate is set to 0.7. In MOEA/D-GA, mutation rate is 0.05 and in NSGA-II, mutation rate is 0.01 .

\subsection{Experiment II: Comparison with Other Distribution- based Mutation Methods}

In this experiment, mutation methods based on four probability distributions, namely Lévy-stable distribution (LEVY), uniform distribution (UNIF), standard normal distribution (NORM) and constant (CONST) are compared to show the effectiveness of LF. Among these four methods, MOEA/D framework and selection method in Lis study Hui Li and Qingfu Zhang, 2009] are applied. The mutation operators of these methods are similar to DE mutation, but the scaling factors are drawn from the above mentioned probability distributions. In addition, two parents are selected in LEVY, while three are selected in the other three mutation methods. As the goal of this experiment is to show how LF contributes to optimization, no polynomial mutation is applied in all methods. Table 3 presents the detailed formula of the mutation methods in Experiment II.

Following the pre-experimental tuning method described in Section 4.1, we 


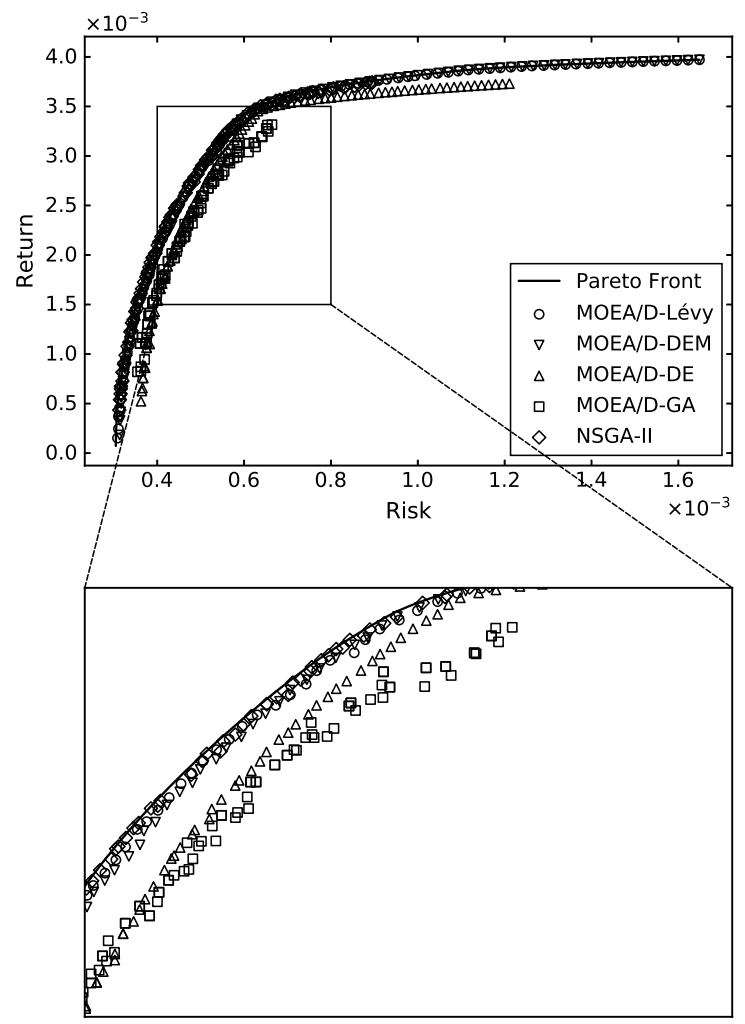

Figure 6: Final population and zoom-in on Nikkei in Experiment I

obtained the following parameter values. Parameter $C$ is set to 1.0 and 0.5 and in UNIF and NORM, respectively. The parameters of LF mutation in LEVY are the same as that of MOEA/D-Lévy in Section 4.2. The parameters of CONST is the same as that of MOEA/D-DE in Section 4.2 It is interesting to notice that CONST and MOEA/D-DE are the same method.

\subsection{Experimental Results}

The reference points used to compute HV are reported in Table 4 The numerical results of both experiments on the five datasets are presented from Table 5 to Table 14. The medians of the best algorithm in each metric are in bold font. In addition, those best medians decorated with underlines indicate that the corresponding algorithms perform better than algorithms with second best medians, through a Wilcoxon Rank Sum Test with a significant level of 5\%. As an example, Fig. 5 shows IGD changing by generations on Nikkei in Experiment 


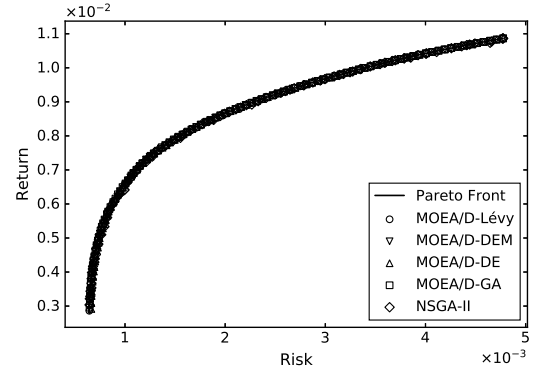

(a) Hangseng

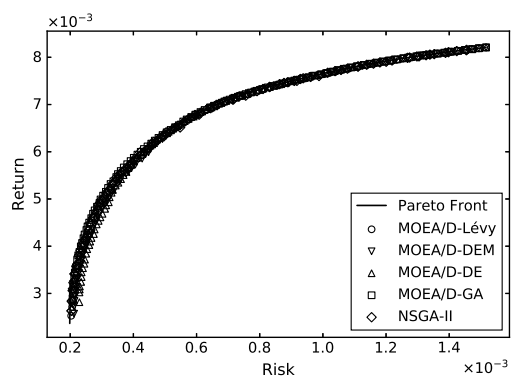

(c) FTSE 100

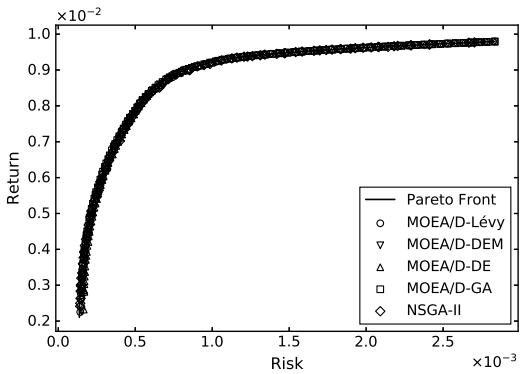

(b) DAX 100

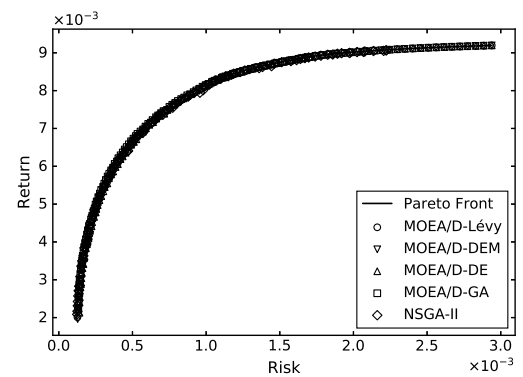

(d) S\&P 100

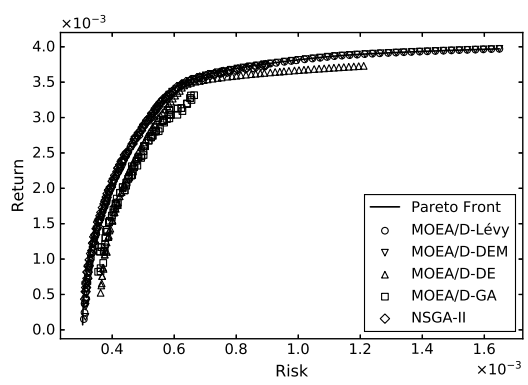

(e) Nikkei

Figure 7: Final population on five datasets in objective space (Experiment I) 


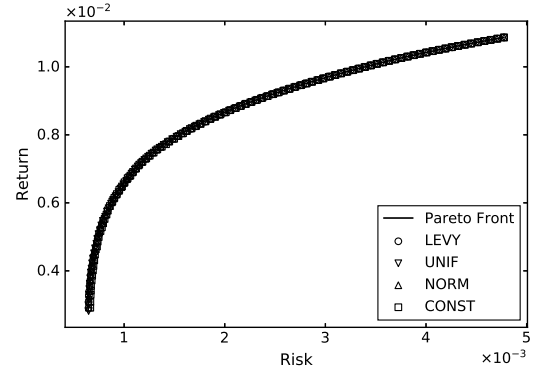

(a) Hangseng

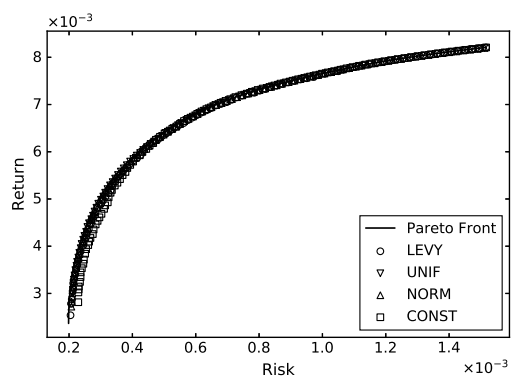

(c) FTSE 100

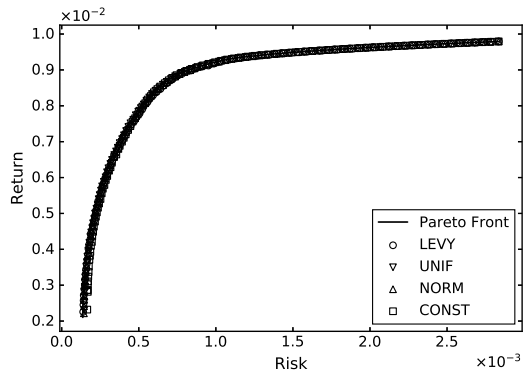

(b) DAX 100

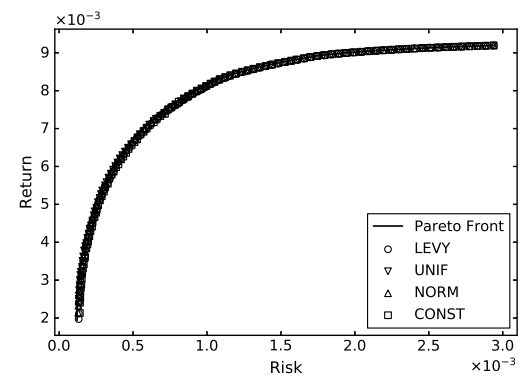

(d) $\mathrm{S} \& \mathrm{P} 100$

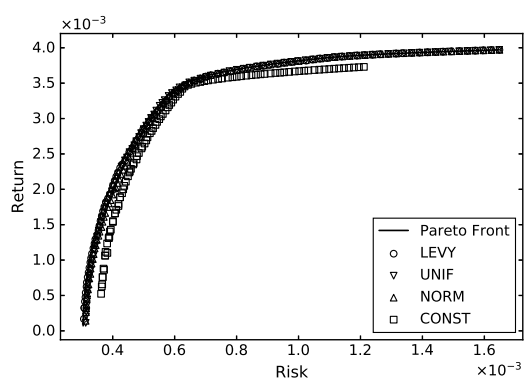

(e) Nikkei

Figure 8: Final population on five datasets in objective space (Experiment II) 


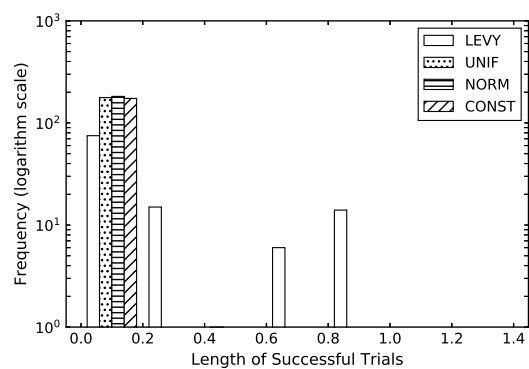

(a) Successful trials

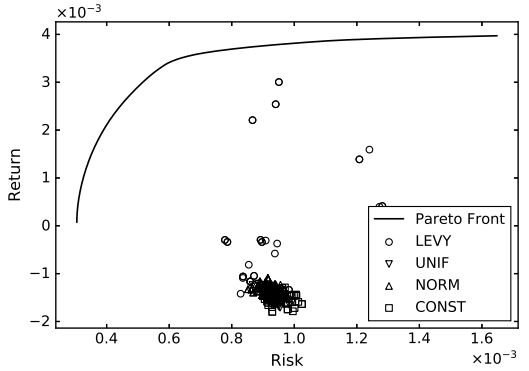

(b) Population in objective space

Figure 9: Experiment II, Nikkei Dataset (1st generation) Left: Frequency of "Succesful trials" (when the mutation operator generates an offspring that is better than its parent) against the length of the mutation step. Right: population in the objective space.

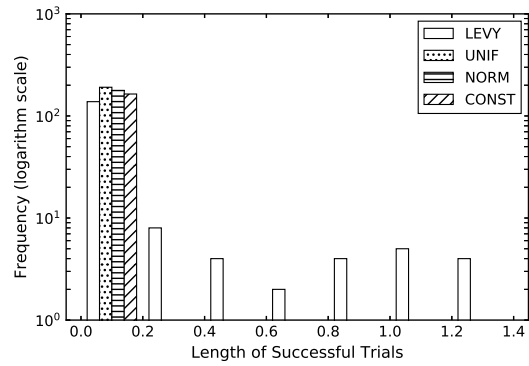

(a) Successful trials

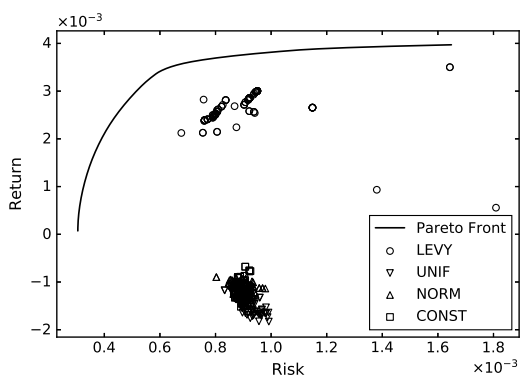

(b) Population in objective space

Figure 10: Experiment II, Nikkei Dataset (3rd generation) Left: Frequency of "Succesful trials" (when the mutation operator generates an offspring that is better than its parent) against the length of the mutation step. Right: population in the objective space. 


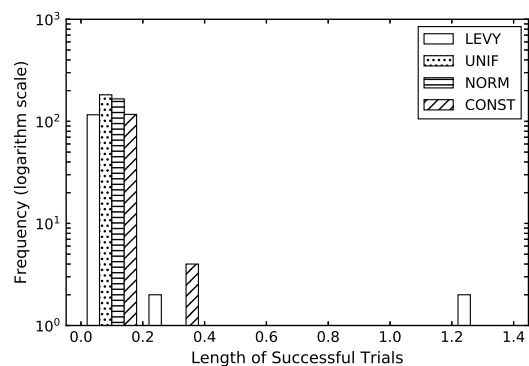

(a) Successful trials

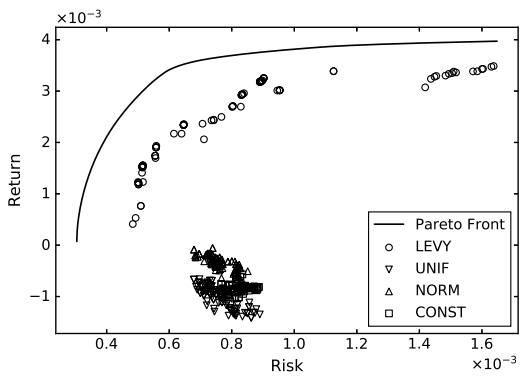

(b) Population in objective space

Figure 11: Experiment II, Nikkei Dataset (10th generation) Left: Frequency of "Succesful trials" (when the mutation operator generates an offspring that is better than its parent) against the length of the mutation step. Right: population in the objective space..

I (best run of IGD). Fig. 6 illustrates the final population on the same dataset and experiment, as well as a zoom-in. The final population of other datasets and experiments are shown in Fig. 7 and 8 . The results for each dataset are detailed as follows.

- Hangseng: In Experiment I, MOEA/D-Lévy holds the best median in terms of MS, $\Delta$ and IGD, while MOEA/D-GA performs best on GD, $\mathrm{S}$, and HV. Both methods show a statistical significance compared with the methods holding the second-best median. In Experiment II, NORM performs best on GD, MS, IGD, and HV. CONST holds the best S, and UNIF holds the best $\Delta$.

- DAX 100: In Experiment I, MOEA/D-Lévy shows a statistically significant superiority in terms of MS, $\Delta$, IGD and HV, while MOEA/D-GA performs better in GD and $\mathrm{S}$ with a statistical significance. In Experiment II, NORM is the best method in terms of five metrics except for S, especially on GD, MS and IGD, the statistical test shows a significant difference. For the S metric, CONST performs best.

- FTSE 100: In Experiment I, MOEA/D-Lévy shows a clear superiority on MS, $\Delta$, IGD and HV, while MOEA/D-GA and MOEA/D-DE perform best on GD and S, respectively. In Experiment II, LEVY performs best on MS, $\Delta$, IGD and HV. On MS and IGD, it shows a statistical significance in the comparison with NORM which holds second place. NORM performs best on GD, while CONST performs best on $\mathrm{S}$.

- S\&P 100: In Experiment I, MOEA/D-Lévy holds the best median on $\Delta$, IGD and HV. Especially, on $\Delta$ and HV, there is a significant difference between the second-best method. MOEA/D-GA, MOEA/D-DE, and 


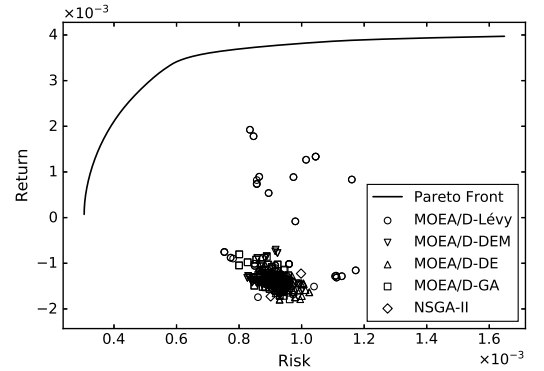

(a) 1st generation

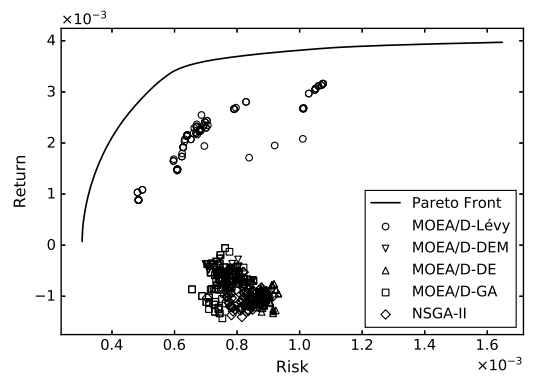

(c) 5th generation

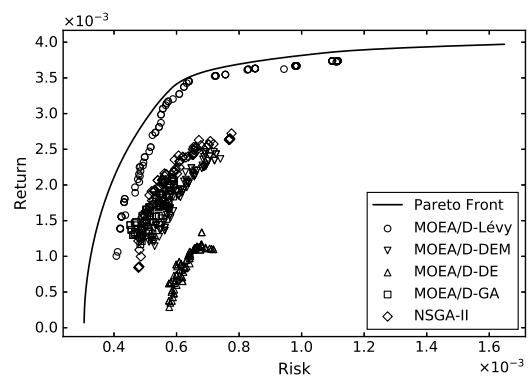

(e) 50th generation

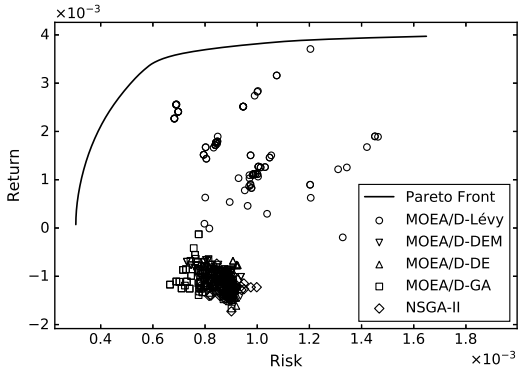

(b) 3rd generation

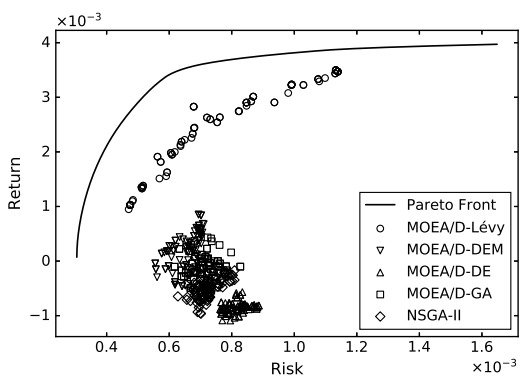

(d) 10th generation

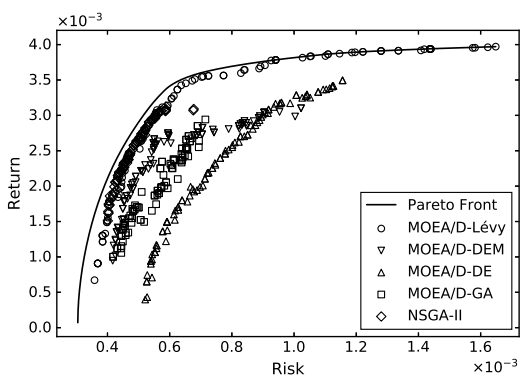

(f) 100th generation

Figure 12: Experiment I: Populations of different algorithms over generations in the Nikkei dataset. MOEA/D-Lévy covers a wider area early in the optimization, which leads to a better distribution over the Pareto Front around the 100th generation. 


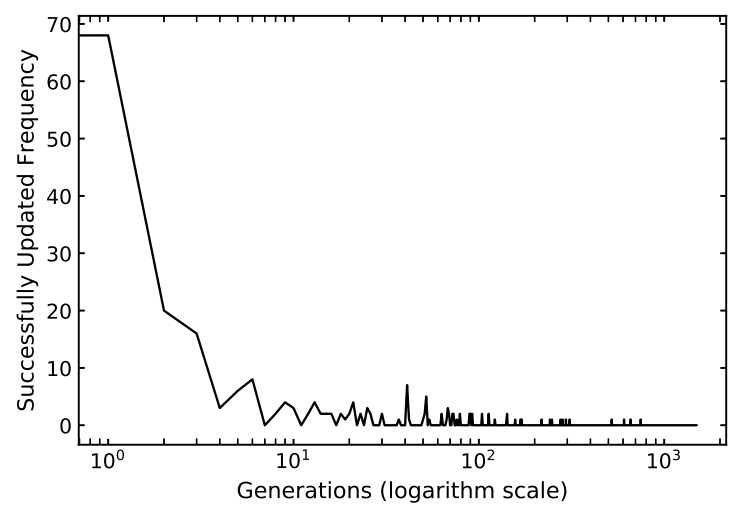

Figure 13: Successfully updated long trials by generations

\section{Parent}

\begin{tabular}{|l|l|l|l|l|l|l|}
\hline 0.10 & 0.15 & 0.20 & 0.15 & 0.18 & 0.02 & 0.20 \\
\hline
\end{tabular}

${ }^{*}$ sum of variables $=1$

Mutation Vector Generated by LF

\begin{tabular}{|l|c|c|c|c|c|c|}
\hline 0.05 & $\mathbf{5 . 0 0}$ & 0.10 & 0.50 & 0.08 & 0.02 & 0.67 \\
\hline
\end{tabular}

* small probability to generate large value

Add mutation vector

to parent

Offspring before Repair

\begin{tabular}{rl|l|l|l|l|l|l|}
\hline 0.15 & $\mathbf{5 . 1 5}$ & 0.30 & 0.65 & 0.26 & 0.04 & 0.87 \\
* sum of variables $=7.42$ \\
$\qquad \begin{array}{l}\text { Repair with method } \\
\text { in Algorithm 2 }\end{array}$
\end{tabular}

Offspring after Repair

\begin{tabular}{|l|c|c|c|c|c|c|}
\hline 0.02 & $\mathbf{0 . 6 9}$ & 0.04 & 0.09 & 0.03 & 0.01 & 0.12 \\
\hline
\end{tabular}
$\begin{aligned} & \text { * re-allocation centralized on one variable } \\
& \text { sum of variables }=1\end{aligned}$

Figure 14: How LF mutation helps exploration in PO. An interaction between long trajectories and unit constraint leads to candidates with high allocation in only some assets. 
MOEA/D-DEM are the best method in terms of GD, S, and MS, respectively. In Experiment II, UNIF holds the best GD and S, while NORM performs best on the rest metrics. LEVY holds the second place on MS, IGD, and $\mathrm{HV}$, and shows a comparable performance.

- Nikkei: In Experiment I, MOEA/D-Lévy performs best on $\Delta$, IGD and $\mathrm{HV}$. Especially, on $\Delta$ and HV, there is a significant difference between the second-best method. NSGA-II, MOEA/D-DE, and MOEA/D-DEM are the best method in terms of GD, S, and MS, respectively. In Experiment II, LEVY shows a significant superiority in terms of GD, MS, $\Delta$, IGD and HV. For S, CONST performs best.

In addition, it is hard to find a difference when considering the plots of the solution distributions. On FTSE 100, the MOEA/D-DE or CONST perform relatively worse on retrieving low-risk portfolio (i.e., they have fewer solutions in the bottom left regions in Fig. $7 \mathrm{C}$ and $8 \mathrm{CC}$. On S\&P 100 and Nikkei, the two GA-based algorithms only retrieve a part of the front (i.e., show in Fig. 7d and 7e). On Nikkei, the solution set retrieved by MOEA/D-DE or CONST is relatively narrow and far from the Pareto Front (i.e., show in Fig. $7 \mathrm{e}$ and 8e).

\section{Discussion}

The numerical results show a good performance of the proposed MOEA/D-Lévy. It is easy to realize that those long trajectories caused by LF can enhance the global search capability of algorithms by comparing the results of LEVY and NORM in Experiment II, as the main difference between a heavy-distribution and standard normal distribution is the occasional generation of large numbers. In this section, we show further insights on how long trajectories contribute to this observed improvement.

To record long trajectories, we compute the Euclidean distance between a repaired offspring $\boldsymbol{y}$ and its parent $\boldsymbol{x}^{\boldsymbol{i}}$ in the mutation methods based on LEVY, UNIF, NORM, and CONST, using Nikkei dataset. This distance is the length of the trial vector. In addition, we record the frequency that this offspring is successfully updated. Based on the parameter settings in Section 4.1, the possible frequency for one offspring is 0,1 or 2. Fig. 9a, 10a and 11a show the frequency of trajectories in different length, at 1st, 3rd and 10th generation in one certain run, respectively. Fig. 9b, 10b and 11b illustrate the corresponding populations at each generation. Fig. 1 shows a population on objective space at 10th generation in Experiment I. Fig. 13 shows the frequency of successfully updated long trajectories (i.e., the length is larger than 0.2 ) by generations in MOEA/D-Lévy in the same run.

It is interesting to notice that there are some long trial vectors successfully updated in the beginning phase of LEVY, while the same observation does not occur in UNIF, NORM, and CONST. These long trajectories usually represent a global search. As a result, LEVY achieves early in the optimization a solution set that is widely spread across the objective space (i.e., show in Fig. $9 b$ 
Table 5: Numerical results on Hangseng in Experiment I

\begin{tabular}{ccccccc}
\hline \multirow{2}{*}{ Metric } & \multicolumn{5}{c}{ MOEA/D } & \multirow{2}{*}{ NSGA-II } \\
\cline { 3 - 6 } GD & Lévy & DEM & DE & GA & \\
\hline \multirow{2}{*}{ Best } & $4.51 \mathrm{E}-06$ & $4.21 \mathrm{E}-06$ & $3.49 \mathrm{E}-06$ & $1.74 \mathrm{E}-06$ & $9.06 \mathrm{E}-06$ \\
& Median & $5.78 \mathrm{E}-06$ & $7.26 \mathrm{E}-06$ & $7.98 \mathrm{E}-06$ & $\mathbf{2 . 2 9 E}-06$ & $1.19 \mathrm{E}-05$ \\
& Std. & $8.78 \mathrm{E}-07$ & $2.22 \mathrm{E}-06$ & $1.18 \mathrm{E}-04$ & $2.60 \mathrm{E}-07$ & $1.34 \mathrm{E}-06$ \\
\hline \multirow{3}{*}{ S } & Best & $1.56 \mathrm{E}-05$ & $1.50 \mathrm{E}-05$ & $8.51 \mathrm{E}-06$ & $9.38 \mathrm{E}-06$ & $3.94 \mathrm{E}-05$ \\
& Median & $2.06 \mathrm{E}-05$ & $2.34 \mathrm{E}-05$ & $1.80 \mathrm{E}-05$ & $\mathbf{1 . 5 3 E - 0 5}$ & $4.92 \mathrm{E}-05$ \\
& Std. & $7.18 \mathrm{E}-06$ & $9.07 \mathrm{E}-06$ & $6.76 \mathrm{E}-06$ & $5.71 \mathrm{E}-06$ & $4.19 \mathrm{E}-06$ \\
\hline \multirow{3}{*}{$\mathrm{MS}$} & Best & $9.13 \mathrm{E}-03$ & $9.23 \mathrm{E}-03$ & $9.00 \mathrm{E}-03$ & $8.92 \mathrm{E}-03$ & $9.06 \mathrm{E}-03$ \\
& Median & $\mathbf{8 . 9 6 E - 0 3}$ & $8.89 \mathrm{E}-03$ & $8.54 \mathrm{E}-03$ & $8.25 \mathrm{E}-03$ & $8.63 \mathrm{E}-03$ \\
& Std. & $1.01 \mathrm{E}-04$ & $1.98 \mathrm{E}-04$ & $9.93 \mathrm{E}-04$ & $3.16 \mathrm{E}-04$ & $2.18 \mathrm{E}-04$ \\
\hline \multirow{4}{*}{$\Delta$} & Best & $2.47 \mathrm{E}-01$ & $2.53 \mathrm{E}-01$ & $2.33 \mathrm{E}-01$ & $2.61 \mathrm{E}-01$ & $4.48 \mathrm{E}-01$ \\
& Median & $\mathbf{2 . 6 4 E - 0 1}$ & $2.87 \mathrm{E}-01$ & $2.87 \mathrm{E}-01$ & $2.80 \mathrm{E}-01$ & $4.94 \mathrm{E}-01$ \\
& Std. & $3.11 \mathrm{E}-02$ & $3.99 \mathrm{E}-02$ & $8.20 \mathrm{E}-02$ & $1.40 \mathrm{E}-02$ & $3.50 \mathrm{E}-02$ \\
\hline \multirow{2}{*}{ IGD } & Best & $2.90 \mathrm{E}-05$ & $2.99 \mathrm{E}-05$ & $3.15 \mathrm{E}-05$ & $2.98 \mathrm{E}-05$ & $3.92 \mathrm{E}-05$ \\
& Median & $\mathbf{3 . 1 3 E - 0 5}$ & $3.50 \mathrm{E}-05$ & $6.03 \mathrm{E}-05$ & $7.54 \mathrm{E}-05$ & $5.01 \mathrm{E}-05$ \\
& Std. & $2.75 \mathrm{E}-06$ & $8.54 \mathrm{E}-06$ & $2.44 \mathrm{E}-04$ & $3.97 \mathrm{E}-05$ & $1.55 \mathrm{E}-05$ \\
\hline \multirow{2}{*}{ HV } & Best & $2.64 \mathrm{E}-05$ & $2.64 \mathrm{E}-05$ & $2.64 \mathrm{E}-05$ & $2.64 \mathrm{E}-05$ & $2.63 \mathrm{E}-05$ \\
& Median & $2.64 \mathrm{E}-05$ & $2.63 \mathrm{E}-05$ & $2.63 \mathrm{E}-05$ & $\mathbf{2 . 6 4 E - 0 5}$ & $2.63 \mathrm{E}-05$ \\
& Std. & $9.76 \mathrm{E}-09$ & $2.64 \mathrm{E}-08$ & $2.21 \mathrm{E}-06$ & $1.38 \mathrm{E}-08$ & $1.31 \mathrm{E}-08$ \\
\hline
\end{tabular}

Table 6: Numerical results on Hangseng in Experiment II

\begin{tabular}{cccccc}
\hline \multicolumn{2}{c}{ Metric } & LEVY & UNIF & NORM & CONST \\
\hline \multirow{4}{*}{ GD } & Best & $4.95 \mathrm{E}-06$ & $4.57 \mathrm{E}-06$ & $4.24 \mathrm{E}-06$ & $3.49 \mathrm{E}-06$ \\
& Median & $8.10 \mathrm{E}-06$ & $7.07 \mathrm{E}-06$ & $\mathbf{7 . 0 2 E - 0 6}$ & $7.98 \mathrm{E}-06$ \\
& Std. & $1.44 \mathrm{E}-06$ & $1.62 \mathrm{E}-06$ & $1.44 \mathrm{E}-06$ & $1.18 \mathrm{E}-04$ \\
\hline \multirow{4}{*}{ S } & Best & $1.43 \mathrm{E}-05$ & $1.43 \mathrm{E}-05$ & $1.37 \mathrm{E}-05$ & $8.51 \mathrm{E}-06$ \\
& Median & $1.98 \mathrm{E}-05$ & $1.83 \mathrm{E}-05$ & $1.85 \mathrm{E}-05$ & $\mathbf{1 . 8 0 E - 0 5}$ \\
& Std. & $4.95 \mathrm{E}-06$ & $4.66 \mathrm{E}-06$ & $4.45 \mathrm{E}-06$ & $6.76 \mathrm{E}-06$ \\
\hline \multirow{4}{*}{ MS } & Best & $9.02 \mathrm{E}-03$ & $9.09 \mathrm{E}-03$ & $9.10 \mathrm{E}-03$ & $9.00 \mathrm{E}-03$ \\
& Median & $8.85 \mathrm{E}-03$ & $8.82 \mathrm{E}-03$ & $\mathbf{8 . 8 6 E - 0 3}$ & $8.54 \mathrm{E}-03$ \\
& Std. & $1.39 \mathrm{E}-04$ & $2.04 \mathrm{E}-04$ & $1.87 \mathrm{E}-04$ & $9.93 \mathrm{E}-04$ \\
\hline \multirow{4}{*}{$\Delta$} & Best & $2.48 \mathrm{E}-01$ & $2.47 \mathrm{E}-01$ & $2.47 \mathrm{E}-01$ & $2.33 \mathrm{E}-01$ \\
& Median & $2.64 \mathrm{E}-01$ & $\mathbf{2 . 6 3 E - 0 1}$ & $2.65 \mathrm{E}-01$ & $2.87 \mathrm{E}-01$ \\
& Std. & $2.26 \mathrm{E}-02$ & $1.94 \mathrm{E}-02$ & $1.60 \mathrm{E}-02$ & $8.20 \mathrm{E}-02$ \\
\hline \multirow{4}{*}{ IGD } & Best & $2.97 \mathrm{E}-05$ & $2.88 \mathrm{E}-05$ & $2.89 \mathrm{E}-05$ & $3.15 \mathrm{E}-05$ \\
& Median & $3.40 \mathrm{E}-05$ & $3.40 \mathrm{E}-05$ & $\mathbf{3 . 2 7 E}-05$ & $6.03 \mathrm{E}-05$ \\
& Std. & $5.92 \mathrm{E}-06$ & $9.76 \mathrm{E}-06$ & $8.27 \mathrm{E}-06$ & $2.44 \mathrm{E}-04$ \\
\hline \multirow{3}{*}{ HV } & Best & $2.64 \mathrm{E}-05$ & $2.64 \mathrm{E}-05$ & $2.64 \mathrm{E}-05$ & $2.64 \mathrm{E}-05$ \\
& Median & $2.63 \mathrm{E}-05$ & $2.64 \mathrm{E}-05$ & $\mathbf{2 . 6 4 E - 0 5}$ & $2.63 \mathrm{E}-05$ \\
& Std. & $1.42 \mathrm{E}-08$ & $1.69 \mathrm{E}-08$ & $1.43 \mathrm{E}-08$ & $2.21 \mathrm{E}-06$ \\
\hline
\end{tabular}


Table 7: Numerical results on DAX 100 in Experiment I

\begin{tabular}{|c|c|c|c|c|c|c|}
\hline \multirow{2}{*}{\multicolumn{2}{|c|}{ Metric }} & \multicolumn{4}{|c|}{ MOEA/D } & \multirow{2}{*}{ NSGA-II } \\
\hline & & Lévy & DEM & $\overline{\mathrm{DE}}$ & GA & \\
\hline \multirow{3}{*}{ GD } & Best & $5.85 \mathrm{E}-06$ & $7.11 \mathrm{E}-06$ & $7.32 \mathrm{E}-06$ & $1.83 \mathrm{E}-06$ & $5.37 \mathrm{E}-06$ \\
\hline & Median & 7.98E-06 & $9.53 \mathrm{E}-06$ & $1.65 \mathrm{E}-05$ & $2.78 \mathrm{E}-06$ & $8.04 \mathrm{E}-06$ \\
\hline & Std. & $1.11 \mathrm{E}-06$ & $1.81 \mathrm{E}-06$ & $9.27 \mathrm{E}-05$ & $6.36 \mathrm{E}-07$ & $1.99 \mathrm{E}-06$ \\
\hline \multirow{3}{*}{ S } & Best & $2.76 \mathrm{E}-05$ & $2.34 \mathrm{E}-05$ & $1.64 \mathrm{E}-05$ & $1.59 \mathrm{E}-05$ & $2.27 \mathrm{E}-05$ \\
\hline & Median & $3.25 \mathrm{E}-05$ & $3.24 \mathrm{E}-05$ & $2.98 \mathrm{E}-05$ & $2.48 \mathrm{E}-05$ & $4.34 \mathrm{E}-05$ \\
\hline & Std. & $7.29 \mathrm{E}-06$ & 7.37E-06 & $6.61 \mathrm{E}-06$ & $5.68 \mathrm{E}-06$ & $6.94 \mathrm{E}-06$ \\
\hline \multirow{3}{*}{ MS } & Best & $8.13 \mathrm{E}-03$ & $8.12 \mathrm{E}-03$ & $8.36 \mathrm{E}-03$ & $7.37 \mathrm{E}-03$ & $7.83 \mathrm{E}-03$ \\
\hline & Median & $\underline{7.77 \mathrm{E}-03}$ & $7.71 \mathrm{E}-03$ & $7.40 \mathrm{E}-03$ & $6.04 \mathrm{E}-03$ & $7.20 \mathrm{E}-03$ \\
\hline & Std. & $1.59 \mathrm{E}-04$ & $2.31 \mathrm{E}-04$ & $7.26 \mathrm{E}-04$ & $3.70 \mathrm{E}-04$ & $5.20 \mathrm{E}-04$ \\
\hline \multirow{3}{*}{$\Delta$} & Best & $3.88 \mathrm{E}-01$ & $4.07 \mathrm{E}-01$ & $3.60 \mathrm{E}-01$ & $4.54 \mathrm{E}-01$ & $5.70 \mathrm{E}-01$ \\
\hline & Median & $\underline{4.07 \mathrm{E}-01}$ & $4.49 \mathrm{E}-01$ & $4.36 \mathrm{E}-01$ & $5.81 \mathrm{E}-01$ & $6.68 \mathrm{E}-01$ \\
\hline & Std. & $\overline{2.72 \mathrm{E}-02}$ & $3.79 \mathrm{E}-02$ & $7.72 \mathrm{E}-02$ & $3.65 \mathrm{E}-02$ & $5.11 \mathrm{E}-02$ \\
\hline \multirow{3}{*}{ IGD } & Best & $3.28 \mathrm{E}-05$ & $3.62 \mathrm{E}-05$ & $4.40 \mathrm{E}-05$ & $7.20 \mathrm{E}-05$ & $4.14 \mathrm{E}-05$ \\
\hline & Median & $\underline{4.16 \mathrm{E}-05}$ & $4.90 \mathrm{E}-05$ & $9.48 \mathrm{E}-05$ & $1.54 \mathrm{E}-04$ & $6.55 \mathrm{E}-05$ \\
\hline & Std. & $7.87 \mathrm{E}-06$ & $1.60 \mathrm{E}-05$ & $9.39 \mathrm{E}-05$ & $3.75 \mathrm{E}-05$ & $3.34 \mathrm{E}-05$ \\
\hline \multirow{3}{*}{$\mathrm{HV}$} & Best & $1.91 \mathrm{E}-05$ & $1.90 \mathrm{E}-05$ & $1.90 \mathrm{E}-05$ & $1.91 \mathrm{E}-05$ & $1.90 \mathrm{E}-05$ \\
\hline & Median & $\underline{1.90 \mathrm{E}-05}$ & $1.90 \mathrm{E}-05$ & $1.89 \mathrm{E}-05$ & $1.84 \mathrm{E}-05$ & $1.90 \mathrm{E}-05$ \\
\hline & Std. & $1.16 \mathrm{E}-08$ & $2.34 \mathrm{E}-08$ & $1.08 \mathrm{E}-06$ & $4.22 \mathrm{E}-07$ & $4.44 \mathrm{E}-07$ \\
\hline
\end{tabular}

Table 8: Numerical results on DAX 100 in Experiment II

\begin{tabular}{cccccc}
\hline \multicolumn{2}{c}{ Metric } & LEVY & UNIF & NORM & CONST \\
\hline \multirow{4}{*}{ GD } & Best & $7.23 \mathrm{E}-06$ & $4.76 \mathrm{E}-06$ & $4.88 \mathrm{E}-06$ & $7.32 \mathrm{E}-06$ \\
& Median & $9.37 \mathrm{E}-06$ & $7.43 \mathrm{E}-06$ & $\mathbf{6 . 8 5 E}-06$ & $1.65 \mathrm{E}-05$ \\
& Std. & $9.63 \mathrm{E}-07$ & $1.39 \mathrm{E}-06$ & $1.47 \mathrm{E}-06$ & $9.27 \mathrm{E}-05$ \\
\hline \multirow{2}{*}{ S } & Best & $2.58 \mathrm{E}-05$ & $2.61 \mathrm{E}-05$ & $2.70 \mathrm{E}-05$ & $1.64 \mathrm{E}-05$ \\
& Median & $3.28 \mathrm{E}-05$ & $3.09 \mathrm{E}-05$ & $3.19 \mathrm{E}-05$ & $\mathbf{2 . 9 8 E - 0 5}$ \\
& Std. & $3.96 \mathrm{E}-06$ & $3.97 \mathrm{E}-06$ & $5.22 \mathrm{E}-06$ & $6.61 \mathrm{E}-06$ \\
\hline \multirow{2}{*}{$\mathrm{MS}$} & Best & $8.00 \mathrm{E}-03$ & $8.02 \mathrm{E}-03$ & $8.13 \mathrm{E}-03$ & $8.36 \mathrm{E}-03$ \\
& Median & $7.75 \mathrm{E}-03$ & $7.76 \mathrm{E}-03$ & $\mathbf{7 . 8 2 E - 0 3}$ & $7.40 \mathrm{E}-03$ \\
& Std. & $1.59 \mathrm{E}-04$ & $1.48 \mathrm{E}-04$ & $1.36 \mathrm{E}-04$ & $7.26 \mathrm{E}-04$ \\
\hline \multirow{4}{*}{$\Delta$} & Best & $3.85 \mathrm{E}-01$ & $3.94 \mathrm{E}-01$ & $3.89 \mathrm{E}-01$ & $3.60 \mathrm{E}-01$ \\
& Median & $4.12 \mathrm{E}-01$ & $4.08 \mathrm{E}-01$ & $\mathbf{4 . 0 7 E}-01$ & $4.36 \mathrm{E}-01$ \\
& Std. & $2.32 \mathrm{E}-02$ & $2.47 \mathrm{E}-02$ & $2.55 \mathrm{E}-02$ & $7.72 \mathrm{E}-02$ \\
\hline \multirow{2}{*}{ IGD } & Best & $3.40 \mathrm{E}-05$ & $3.34 \mathrm{E}-05$ & $3.20 \mathrm{E}-05$ & $4.40 \mathrm{E}-05$ \\
& Median & $4.39 \mathrm{E}-05$ & $4.07 \mathrm{E}-05$ & $\mathbf{3 . 8 3 E - 0 5}$ & $9.48 \mathrm{E}-05$ \\
& Std. & $1.14 \mathrm{E}-05$ & $7.89 \mathrm{E}-06$ & $5.77 \mathrm{E}-06$ & $9.39 \mathrm{E}-05$ \\
\hline \multirow{2}{*}{ HV } & Best & $1.90 \mathrm{E}-05$ & $1.91 \mathrm{E}-05$ & $1.91 \mathrm{E}-05$ & $1.90 \mathrm{E}-05$ \\
& Median & $1.90 \mathrm{E}-05$ & $1.90 \mathrm{E}-05$ & $\mathbf{1 . 9 0 E - 0 5}$ & $1.89 \mathrm{E}-05$ \\
& Std. & $1.19 \mathrm{E}-08$ & $1.28 \mathrm{E}-08$ & $1.50 \mathrm{E}-08$ & $1.08 \mathrm{E}-06$ \\
\hline
\end{tabular}


Table 9: Numerical results on FTSE 100 in Experiment I

\begin{tabular}{ccccccc}
\hline \multirow{2}{*}{ Metric } & \multicolumn{5}{c}{ MOEA/D } & \multirow{2}{*}{ NSGA-II } \\
\cline { 3 - 6 } GD & Lévy & DEM & DE & GA & \\
\hline \multirow{2}{*}{ Gest } & $5.39 \mathrm{E}-06$ & $6.32 \mathrm{E}-06$ & $7.01 \mathrm{E}-06$ & $2.84 \mathrm{E}-06$ & $7.38 \mathrm{E}-06$ \\
& Median & $7.12 \mathrm{E}-06$ & $9.58 \mathrm{E}-06$ & $1.83 \mathrm{E}-05$ & $\mathbf{5 . 0 5 E}-06$ & $9.25 \mathrm{E}-06$ \\
& Std. & $7.30 \mathrm{E}-07$ & $2.41 \mathrm{E}-06$ & $1.55 \mathrm{E}-04$ & $1.60 \mathrm{E}-06$ & $9.51 \mathrm{E}-07$ \\
\hline \multirow{3}{*}{ S } & Best & $1.59 \mathrm{E}-05$ & $1.38 \mathrm{E}-05$ & $9.87 \mathrm{E}-06$ & $1.14 \mathrm{E}-05$ & $2.39 \mathrm{E}-05$ \\
& Median & $2.09 \mathrm{E}-05$ & $2.01 \mathrm{E}-05$ & $\mathbf{1 . 7 2 E}-05$ & $1.97 \mathrm{E}-05$ & $2.99 \mathrm{E}-05$ \\
& Std. & $3.96 \mathrm{E}-06$ & $4.54 \mathrm{E}-06$ & $3.34 \mathrm{E}-06$ & $5.10 \mathrm{E}-06$ & $2.24 \mathrm{E}-06$ \\
\hline \multirow{3}{*}{$\mathrm{MS}$} & Best & $5.85 \mathrm{E}-03$ & $5.79 \mathrm{E}-03$ & $5.74 \mathrm{E}-03$ & $5.47 \mathrm{E}-03$ & $5.67 \mathrm{E}-03$ \\
& Median & $\mathbf{5 . 5 4 E - 0 3}$ & $5.40 \mathrm{E}-03$ & $5.15 \mathrm{E}-03$ & $4.91 \mathrm{E}-03$ & $5.45 \mathrm{E}-03$ \\
& Std. & $1.46 \mathrm{E}-04$ & $1.93 \mathrm{E}-04$ & $5.08 \mathrm{E}-04$ & $4.19 \mathrm{E}-04$ & $1.69 \mathrm{E}-04$ \\
\hline \multirow{3}{*}{$\Delta$} & Best & $4.06 \mathrm{E}-01$ & $4.25 \mathrm{E}-01$ & $4.21 \mathrm{E}-01$ & $4.27 \mathrm{E}-01$ & $5.47 \mathrm{E}-01$ \\
& Median & $\mathbf{4 . 3 3 E - 0 1}$ & $4.72 \mathrm{E}-01$ & $4.51 \mathrm{E}-01$ & $5.05 \mathrm{E}-01$ & $6.06 \mathrm{E}-01$ \\
& Std. & $3.38 \mathrm{E}-02$ & $3.06 \mathrm{E}-02$ & $6.30 \mathrm{E}-02$ & $6.88 \mathrm{E}-02$ & $3.32 \mathrm{E}-02$ \\
\hline \multirow{3}{*}{ IGD } & Best & $2.36 \mathrm{E}-05$ & $2.90 \mathrm{E}-05$ & $4.26 \mathrm{E}-05$ & $4.07 \mathrm{E}-05$ & $3.22 \mathrm{E}-05$ \\
& Median & $\mathbf{3 . 8 3 E - 0 5}$ & $5.31 \mathrm{E}-05$ & $9.09 \mathrm{E}-05$ & $8.76 \mathrm{E}-05$ & $4.74 \mathrm{E}-05$ \\
& Std. & $1.08 \mathrm{E}-05$ & $2.16 \mathrm{E}-05$ & $1.47 \mathrm{E}-04$ & $4.33 \mathrm{E}-05$ & $1.38 \mathrm{E}-05$ \\
\hline \multirow{2}{*}{ HV } & Best & $1.37 \mathrm{E}-05$ & $1.37 \mathrm{E}-05$ & $1.37 \mathrm{E}-05$ & $1.37 \mathrm{E}-05$ & $1.37 \mathrm{E}-05$ \\
& Median & $\mathbf{1 . 3 7 E - 0 5}$ & $1.37 \mathrm{E}-05$ & $1.36 \mathrm{E}-05$ & $1.34 \mathrm{E}-05$ & $1.37 \mathrm{E}-05$ \\
& Std. & $\mathbf{5 . 7 2 E - 0 9}$ & $1.64 \mathrm{E}-08$ & $1.36 \mathrm{E}-06$ & $6.19 \mathrm{E}-07$ & $8.35 \mathrm{E}-08$ \\
\hline
\end{tabular}

Table 10: Numerical results on FTSE 100 in Experiment II

\begin{tabular}{cccccc}
\hline \multicolumn{2}{c}{ Metric } & LEVY & UNIF & NORM & CONST \\
\hline \multirow{4}{*}{ GD } & Best & $6.56 \mathrm{E}-06$ & $5.58 \mathrm{E}-06$ & $4.83 \mathrm{E}-06$ & $7.01 \mathrm{E}-06$ \\
& Median & $8.48 \mathrm{E}-06$ & $8.26 \mathrm{E}-06$ & $\mathbf{7 . 2 6 E - 0 6}$ & $1.83 \mathrm{E}-05$ \\
& Std. & $1.12 \mathrm{E}-06$ & $2.24 \mathrm{E}-06$ & $5.79 \mathrm{E}-05$ & $1.55 \mathrm{E}-04$ \\
\hline \multirow{3}{*}{ S } & Best & $1.73 \mathrm{E}-05$ & $1.51 \mathrm{E}-05$ & $1.62 \mathrm{E}-05$ & $9.87 \mathrm{E}-06$ \\
& Median & $2.06 \mathrm{E}-05$ & $1.75 \mathrm{E}-05$ & $1.87 \mathrm{E}-05$ & $\mathbf{1 . 7 2 E - 0 5}$ \\
& Std. & $3.94 \mathrm{E}-06$ & $1.56 \mathrm{E}-06$ & $3.02 \mathrm{E}-06$ & $3.34 \mathrm{E}-06$ \\
\hline \multirow{3}{*}{ MS } & Best & $5.82 \mathrm{E}-03$ & $5.48 \mathrm{E}-03$ & $5.69 \mathrm{E}-03$ & $5.74 \mathrm{E}-03$ \\
& Median & $\mathbf{5 . 4 7 E - 0 3}$ & $5.19 \mathrm{E}-03$ & $5.35 \mathrm{E}-03$ & $5.15 \mathrm{E}-03$ \\
& Std. & $1.54 \mathrm{E}-04$ & $1.29 \mathrm{E}-04$ & $2.07 \mathrm{E}-04$ & $5.08 \mathrm{E}-04$ \\
\hline \multirow{4}{*}{$\Delta$} & Best & $4.09 \mathrm{E}-01$ & $4.19 \mathrm{E}-01$ & $4.13 \mathrm{E}-01$ & $4.21 \mathrm{E}-01$ \\
& Median & $\mathbf{4 . 3 5 E - 0 1}$ & $4.45 \mathrm{E}-01$ & $4.36 \mathrm{E}-01$ & $4.51 \mathrm{E}-01$ \\
& Std. & $2.03 \mathrm{E}-02$ & $1.13 \mathrm{E}-02$ & $2.60 \mathrm{E}-02$ & $6.30 \mathrm{E}-02$ \\
\hline \multirow{2}{*}{ IGD } & Best & $2.62 \mathrm{E}-05$ & $3.95 \mathrm{E}-05$ & $3.02 \mathrm{E}-05$ & $4.26 \mathrm{E}-05$ \\
& Median & $\mathbf{4 . 2 9 E - 0 5}$ & $7.26 \mathrm{E}-05$ & $5.51 \mathrm{E}-05$ & $9.09 \mathrm{E}-05$ \\
& Std. & $1.27 \mathrm{E}-05$ & $1.66 \mathrm{E}-05$ & $4.61 \mathrm{E}-05$ & $1.47 \mathrm{E}-04$ \\
\hline \multirow{2}{*}{ HV } & Best & $1.37 \mathrm{E}-05$ & $1.37 \mathrm{E}-05$ & $1.37 \mathrm{E}-05$ & $1.37 \mathrm{E}-05$ \\
& Median & $\mathbf{1 . 3 7 E - 0 5}$ & $1.37 \mathrm{E}-05$ & $1.37 \mathrm{E}-05$ & $1.36 \mathrm{E}-05$ \\
& Std. & $8.46 \mathrm{E}-09$ & $2.48 \mathrm{E}-08$ & $4.42 \mathrm{E}-07$ & $1.36 \mathrm{E}-06$ \\
\hline
\end{tabular}


Table 11: Numerical results on S\&P 100 in Experiment I

\begin{tabular}{|c|c|c|c|c|c|c|}
\hline \multirow{2}{*}{\multicolumn{2}{|c|}{ Metric }} & \multicolumn{4}{|c|}{ MOEA/D } & \multirow{2}{*}{ NSGA-II } \\
\hline & & Lévy & DEM & $\overline{\mathrm{DE}}$ & GA & \\
\hline \multirow{3}{*}{ GD } & Best & $1.05 \mathrm{E}-05$ & $1.13 \mathrm{E}-05$ & $1.27 \mathrm{E}-05$ & $3.20 \mathrm{E}-06$ & $1.01 \mathrm{E}-05$ \\
\hline & Median & $1.25 \mathrm{E}-05$ & $1.75 \mathrm{E}-05$ & $3.92 \mathrm{E}-05$ & $\underline{5.02 \mathrm{E}-06}$ & $1.29 \mathrm{E}-05$ \\
\hline & Std. & $1.64 \mathrm{E}-06$ & $3.45 \mathrm{E}-06$ & 7.64E-05 & $\overline{1.86 \mathrm{E}-06}$ & $1.42 \mathrm{E}-06$ \\
\hline \multirow{3}{*}{$\mathrm{S}$} & Best & $2.08 \mathrm{E}-05$ & $2.01 \mathrm{E}-05$ & $1.72 \mathrm{E}-05$ & $1.77 \mathrm{E}-05$ & $2.51 \mathrm{E}-05$ \\
\hline & Median & $2.51 \mathrm{E}-05$ & $2.76 \mathrm{E}-05$ & $2.31 \mathrm{E}-05$ & $2.35 \mathrm{E}-05$ & $3.58 \mathrm{E}-05$ \\
\hline & Std. & $5.10 \mathrm{E}-06$ & $5.26 \mathrm{E}-06$ & $4.78 \mathrm{E}-06$ & $5.06 \mathrm{E}-06$ & $3.68 \mathrm{E}-06$ \\
\hline \multirow{3}{*}{ MS } & Best & $7.72 \mathrm{E}-03$ & $7.86 \mathrm{E}-03$ & $7.60 \mathrm{E}-03$ & $6.87 \mathrm{E}-03$ & $7.29 \mathrm{E}-03$ \\
\hline & Median & $7.44 \mathrm{E}-03$ & $\underline{7.55 \mathrm{E}-03}$ & $7.23 \mathrm{E}-03$ & $5.82 \mathrm{E}-03$ & $6.57 \mathrm{E}-03$ \\
\hline & Std. & $1.47 \mathrm{E}-04$ & $1.61 \mathrm{E}-04$ & $2.53 \mathrm{E}-04$ & $4.35 \mathrm{E}-04$ & $3.52 \mathrm{E}-04$ \\
\hline \multirow{3}{*}{$\Delta$} & Best & $3.29 \mathrm{E}-01$ & $3.30 \mathrm{E}-01$ & $3.29 \mathrm{E}-01$ & $4.22 \mathrm{E}-01$ & $5.37 \mathrm{E}-01$ \\
\hline & Median & $\underline{3.45 \mathrm{E}-01}$ & $3.74 \mathrm{E}-01$ & 3.66E-01 & $5.57 \mathrm{E}-01$ & $6.48 \mathrm{E}-01$ \\
\hline & Std. & $\overline{2.95 \mathrm{E}-02}$ & 3.37E-02 & $2.41 \mathrm{E}-02$ & $3.88 \mathrm{E}-02$ & $3.71 \mathrm{E}-02$ \\
\hline \multirow{3}{*}{ IGD } & Best & $3.30 \mathrm{E}-05$ & $3.30 \mathrm{E}-05$ & $3.64 \mathrm{E}-05$ & $4.88 \mathrm{E}-05$ & $4.08 \mathrm{E}-05$ \\
\hline & Median & 3.97E-05 & $4.35 \mathrm{E}-05$ & $7.12 \mathrm{E}-05$ & $1.36 \mathrm{E}-04$ & $7.08 \mathrm{E}-05$ \\
\hline & Std. & $9.23 \mathrm{E}-06$ & $7.65 \mathrm{E}-06$ & $4.16 \mathrm{E}-05$ & $4.13 \mathrm{E}-05$ & $2.21 \mathrm{E}-05$ \\
\hline \multirow{3}{*}{$\mathrm{HV}$} & Best & $1.87 \mathrm{E}-05$ & $1.87 \mathrm{E}-05$ & $1.87 \mathrm{E}-05$ & $1.87 \mathrm{E}-05$ & $1.87 \mathrm{E}-05$ \\
\hline & Median & $\underline{1.87 \mathrm{E}-05}$ & $1.86 \mathrm{E}-05$ & $1.85 \mathrm{E}-05$ & $1.79 \mathrm{E}-05$ & $1.83 \mathrm{E}-05$ \\
\hline & Std. & $1.51 \mathrm{E}-08$ & $3.19 \mathrm{E}-08$ & $4.79 \mathrm{E}-07$ & $5.03 \mathrm{E}-07$ & $3.13 \mathrm{E}-07$ \\
\hline
\end{tabular}

Table 12: Numerical results on S\&P 100 in Experiment II

\begin{tabular}{cccccc}
\hline \multicolumn{2}{c}{ Metric } & LEVY & UNIF & NORM & CONST \\
\hline \multirow{4}{*}{ GD } & Best & $1.09 \mathrm{E}-05$ & $7.66 \mathrm{E}-06$ & $7.01 \mathrm{E}-06$ & $1.27 \mathrm{E}-05$ \\
& Median & $1.41 \mathrm{E}-05$ & $\mathbf{1 . 0 1 E - 0 5}$ & $1.04 \mathrm{E}-05$ & $3.92 \mathrm{E}-05$ \\
& Std. & $1.83 \mathrm{E}-06$ & $2.67 \mathrm{E}-05$ & $2.99 \mathrm{E}-05$ & $7.64 \mathrm{E}-05$ \\
\hline \multirow{4}{*}{ S } & Best & $2.20 \mathrm{E}-05$ & $2.07 \mathrm{E}-05$ & $2.07 \mathrm{E}-05$ & $1.72 \mathrm{E}-05$ \\
& Median & $2.58 \mathrm{E}-05$ & $\mathbf{2 . 2 9 E}-05$ & $2.42 \mathrm{E}-05$ & $2.31 \mathrm{E}-05$ \\
& Std. & $4.15 \mathrm{E}-06$ & $2.61 \mathrm{E}-06$ & $4.55 \mathrm{E}-06$ & $4.78 \mathrm{E}-06$ \\
\hline \multirow{4}{*}{ MS } & Best & $7.75 \mathrm{E}-03$ & $7.47 \mathrm{E}-03$ & $7.64 \mathrm{E}-03$ & $7.60 \mathrm{E}-03$ \\
& Median & $7.32 \mathrm{E}-03$ & $7.20 \mathrm{E}-03$ & $\mathbf{7 . 3 5 E}-03$ & $7.23 \mathrm{E}-03$ \\
& Std. & $1.60 \mathrm{E}-04$ & $1.33 \mathrm{E}-04$ & $1.65 \mathrm{E}-04$ & $2.53 \mathrm{E}-04$ \\
\hline \multirow{4}{*}{ Delta } & Best & $3.28 \mathrm{E}-01$ & $3.32 \mathrm{E}-01$ & $3.30 \mathrm{E}-01$ & $3.29 \mathrm{E}-01$ \\
& Median & $3.55 \mathrm{E}-01$ & $3.49 \mathrm{E}-01$ & $\mathbf{3 . 4 9 E}-01$ & $3.66 \mathrm{E}-01$ \\
& Std. & $2.04 \mathrm{E}-02$ & $1.86 \mathrm{E}-02$ & $3.04 \mathrm{E}-02$ & $2.41 \mathrm{E}-02$ \\
\hline \multirow{2}{*}{ IGD } & Best & $3.35 \mathrm{E}-05$ & $3.62 \mathrm{E}-05$ & $3.12 \mathrm{E}-05$ & $3.64 \mathrm{E}-05$ \\
& Median & $4.72 \mathrm{E}-05$ & $5.23 \mathrm{E}-05$ & $\mathbf{4 . 2 8 E - 0 5}$ & $7.12 \mathrm{E}-05$ \\
& Std. & $1.11 \mathrm{E}-05$ & $1.42 \mathrm{E}-05$ & $1.31 \mathrm{E}-05$ & $4.16 \mathrm{E}-05$ \\
\hline \multirow{2}{*}{ HV } & Best & $1.87 \mathrm{E}-05$ & $1.87 \mathrm{E}-05$ & $1.88 \mathrm{E}-05$ & $1.87 \mathrm{E}-05$ \\
& Median & $1.87 \mathrm{E}-05$ & $1.87 \mathrm{E}-05$ & $\mathbf{1 . 8 7 E}-05$ & $1.85 \mathrm{E}-05$ \\
& Std. & $1.73 \mathrm{E}-08$ & $1.65 \mathrm{E}-07$ & $1.78 \mathrm{E}-07$ & $4.79 \mathrm{E}-07$ \\
\hline
\end{tabular}


Table 13: Numerical results on Nikkei in Experiment I

\begin{tabular}{|c|c|c|c|c|c|c|}
\hline \multirow{2}{*}{\multicolumn{2}{|c|}{ Metric }} & \multicolumn{4}{|c|}{ MOEA/D } & \multirow{2}{*}{ NSGA-II } \\
\hline & & Lévy & DEM & $\overline{\mathrm{DE}}$ & GA & \\
\hline \multirow{3}{*}{ GD } & Best & $5.45 \mathrm{E}-06$ & $5.10 \mathrm{E}-06$ & $5.93 \mathrm{E}-05$ & $9.95 \mathrm{E}-06$ & $2.54 \mathrm{E}-06$ \\
\hline & Median & $7.26 \mathrm{E}-06$ & $8.06 \mathrm{E}-06$ & $1.45 \mathrm{E}-04$ & $3.31 \mathrm{E}-05$ & $\underline{4.24 \mathrm{E}-06}$ \\
\hline & Std. & $1.16 \mathrm{E}-06$ & $1.66 \mathrm{E}-04$ & $7.09 \mathrm{E}-05$ & $2.08 \mathrm{E}-04$ & $2.01 \mathrm{E}-06$ \\
\hline \multirow{3}{*}{$\mathrm{S}$} & Best & $1.28 \mathrm{E}-05$ & $1.28 \mathrm{E}-05$ & $5.99 \mathrm{E}-06$ & $0.00 \mathrm{E}+00$ & $1.05 \mathrm{E}-05$ \\
\hline & Median & $1.76 \mathrm{E}-05$ & $2.08 \mathrm{E}-05$ & $1.15 \mathrm{E}-05$ & $1.92 \mathrm{E}-05$ & $1.45 \mathrm{E}-05$ \\
\hline & Std. & $2.88 \mathrm{E}-06$ & $5.77 \mathrm{E}-06$ & $4.53 \mathrm{E}-06$ & $9.72 \mathrm{E}-06$ & $1.84 \mathrm{E}-06$ \\
\hline \multirow{3}{*}{ MS } & Best & $4.09 \mathrm{E}-03$ & $4.23 \mathrm{E}-03$ & $4.29 \mathrm{E}-03$ & $2.63 \mathrm{E}-03$ & $3.36 \mathrm{E}-03$ \\
\hline & Median & 3.93E-03 & $3.94 \mathrm{E}-03$ & $2.96 \mathrm{E}-03$ & $2.20 \mathrm{E}-03$ & $2.88 \mathrm{E}-03$ \\
\hline & Std. & $1.38 \mathrm{E}-04$ & $5.39 \mathrm{E}-04$ & $5.48 \mathrm{E}-04$ & $4.65 \mathrm{E}-04$ & $2.54 \mathrm{E}-04$ \\
\hline \multirow{3}{*}{$\Delta$} & Best & $3.94 \mathrm{E}-01$ & $3.99 \mathrm{E}-01$ & $3.17 \mathrm{E}-01$ & $8.40 \mathrm{E}-01$ & $6.09 \mathrm{E}-01$ \\
\hline & Median & $\underline{4.34 \mathrm{E}-01}$ & $4.81 \mathrm{E}-01$ & $5.58 \mathrm{E}-01$ & $9.34 \mathrm{E}-01$ & $6.81 \mathrm{E}-01$ \\
\hline & Std. & $\overline{3.89 \mathrm{E}-02}$ & $9.05 \mathrm{E}-02$ & $1.00 \mathrm{E}-01$ & $3.54 \mathrm{E}-02$ & $2.95 \mathrm{E}-02$ \\
\hline \multirow{3}{*}{ IGD } & Best & $1.77 \mathrm{E}-05$ & $1.90 \mathrm{E}-05$ & $7.90 \mathrm{E}-05$ & $1.77 \mathrm{E}-04$ & $4.64 \mathrm{E}-05$ \\
\hline & Median & 2.39E-05 & $2.73 \mathrm{E}-05$ & $2.23 \mathrm{E}-04$ & $2.41 \mathrm{E}-04$ & $9.69 \mathrm{E}-05$ \\
\hline & Std. & $1.15 \mathrm{E}-05$ & 4.09E-04 & $6.95 \mathrm{E}-05$ & $5.29 \mathrm{E}-04$ & $3.67 \mathrm{E}-05$ \\
\hline \multirow{3}{*}{$\mathrm{HV}$} & Best & $8.31 \mathrm{E}-06$ & $8.29 \mathrm{E}-06$ & $7.96 \mathrm{E}-06$ & $7.87 \mathrm{E}-06$ & $8.19 \mathrm{E}-06$ \\
\hline & Median & $\underline{8.29 \mathrm{E}-06}$ & $8.26 \mathrm{E}-06$ & $7.23 \mathrm{E}-06$ & $7.54 \mathrm{E}-06$ & $7.94 \mathrm{E}-06$ \\
\hline & Std. & $1.59 \mathrm{E}-08$ & $9.52 \mathrm{E}-07$ & $3.43 \mathrm{E}-07$ & $1.20 \mathrm{E}-06$ & $1.08 \mathrm{E}-07$ \\
\hline
\end{tabular}

Table 14: Numerical results on Nikkei in Experiment II

\begin{tabular}{|c|c|c|c|c|c|}
\hline \multicolumn{2}{|c|}{ Metric } & LEVY & UNIF & NORM & CONST \\
\hline \multirow{3}{*}{ GD } & Best & $5.92 \mathrm{E}-06$ & $5.45 \mathrm{E}-06$ & $5.38 \mathrm{E}-06$ & $5.93 \mathrm{E}-05$ \\
\hline & Median & $7.71 \mathrm{E}-06$ & $4.25 \mathrm{E}-05$ & $4.10 \mathrm{E}-05$ & $1.45 \mathrm{E}-04$ \\
\hline & Std. & $1.42 \mathrm{E}-06$ & $1.93 \mathrm{E}-04$ & $2.65 \mathrm{E}-05$ & $7.09 \mathrm{E}-05$ \\
\hline \multirow{3}{*}{$\mathrm{S}$} & Best & $9.54 \mathrm{E}-06$ & $1.24 \mathrm{E}-05$ & $8.75 \mathrm{E}-06$ & $5.99 \mathrm{E}-06$ \\
\hline & Median & $1.66 \mathrm{E}-05$ & $1.54 \mathrm{E}-05$ & $1.50 \mathrm{E}-05$ & $1.15 \mathrm{E}-05$ \\
\hline & Std. & $5.35 \mathrm{E}-06$ & $2.62 \mathrm{E}-06$ & $3.05 \mathrm{E}-06$ & $4.53 \mathrm{E}-06$ \\
\hline \multirow{3}{*}{ MS } & Best & $4.14 \mathrm{E}-03$ & $4.08 \mathrm{E}-03$ & $4.07 \mathrm{E}-03$ & $4.29 \mathrm{E}-03$ \\
\hline & Median & 3.90E-03 & $3.68 \mathrm{E}-03$ & $3.70 \mathrm{E}-03$ & $2.96 \mathrm{E}-03$ \\
\hline & Std. & $1.57 \mathrm{E}-04$ & $5.59 \mathrm{E}-04$ & $3.12 \mathrm{E}-04$ & $5.48 \mathrm{E}-04$ \\
\hline \multirow{3}{*}{$\Delta$} & Best & $3.89 \mathrm{E}-01$ & $3.84 \mathrm{E}-01$ & $3.76 \mathrm{E}-01$ & $3.17 \mathrm{E}-01$ \\
\hline & Median & 4.33E-01 & $4.44 \mathrm{E}-01$ & $4.55 \mathrm{E}-01$ & $5.58 \mathrm{E}-01$ \\
\hline & Std. & $5.61 \mathrm{E}-02$ & $9.82 \mathrm{E}-02$ & $6.73 \mathrm{E}-02$ & $1.00 \mathrm{E}-01$ \\
\hline \multirow{3}{*}{ IGD } & Best & $1.84 \mathrm{E}-05$ & $1.83 \mathrm{E}-05$ & $1.95 \mathrm{E}-05$ & $7.90 \mathrm{E}-05$ \\
\hline & Median & 2.72E-05 & $4.16 \mathrm{E}-05$ & $4.85 \mathrm{E}-05$ & $2.23 \mathrm{E}-04$ \\
\hline & Std. & $1.68 \mathrm{E}-05$ & $4.51 \mathrm{E}-04$ & $2.98 \mathrm{E}-05$ & $6.95 \mathrm{E}-05$ \\
\hline \multirow{3}{*}{$\mathrm{HV}$} & Best & $8.31 \mathrm{E}-06$ & $8.29 \mathrm{E}-06$ & $8.28 \mathrm{E}-06$ & $7.96 \mathrm{E}-06$ \\
\hline & Median & $8.29 \mathrm{E}-06$ & $8.11 \mathrm{E}-06$ & $8.10 \mathrm{E}-06$ & $7.23 \mathrm{E}-06$ \\
\hline & Std. & $2.80 \mathrm{E}-08$ & $9.83 \mathrm{E}-07$ & $1.34 \mathrm{E}-07$ & $3.43 \mathrm{E}-07$ \\
\hline
\end{tabular}


and Fig. 10b). In Fig. 1 and 11b, methods based on LF form a relatively better front than other methods. Fig. 12a to Fig. 12f illustrates the population of five algorithms in Experiment I at different generations in a certain run. In the beginning phase of the optimization, MOEA/D-Lévy forms multiple "sub-sets" while the other methods hold only one front. This may indicate that methods based on LF can search multiple areas at the same time, while other mutations can only deal with one.

To explain this behavior, consider that, in PO, trial vectors or trajectories represent the re-allocation of capital. The heavy-tail distribution holds a large probability to generate small values, and a small probability to generate large values. Fig. 14 presents an example of this procedure. The variable (asset) that receives a large number during mutation will get more capital allocation. What is more, to satisfy the constrain that the summation of variables equals 1 in (3), the repair steps will implement proper scaling, and thus the other variables (assets) will be reduced. Therefore, the re-allocation of capital will be centralized on some assets rather than equally distributed across all assets. If these assets hold relatively high returns, the algorithm can find portfolio candidates with high returns early in the optimization. As the initial population is centralized at the low-risk area in objective space because of the uniform initialization, this mutated candidate has a large probability to be successfully updated. Following this procedure, the solution set will be distributed in multiple areas on the search space. Then, the algorithm will mainly update solutions by local search but in multiple search areas, as the accepted long trials decrease by generation in Fig. 13. Such different search patterns may lead to the observed improvement compared with other methods.

\section{Conclusions}

In this study, we have proposed a novel method to solve the MOOP formulation of PO by injecting LF into MOEA/D as a mutation method. The simulation results have indicated that the proposed method holds better performance in most cases, compared with MOEA/D-DEM, MOEA/D-DE, MOEA/D-GA, and NSGA-II. In addition, we have compared the LF mutation with three other probability-based mutations. On the largest benchmark, Nikkei, LEVY shows better performance. Further insight into the evolutionary process indicated that algorithms based on LF mutation promote global search at the beginning and search multiple areas of the objective space at the same time. This search strategy contributes to improvement.

In the future, we want to extend the proposed method to a more constrained PO to study how LF work with constraints. In Fig. 13, few long trajectories get successfully updated with the generation increased. Thus, we may design an adaptive strategy to reduce global search but enhance local search in the middle and ending period of optimization. It is also interesting to apply this method on other resource allocation problems. 


\section{Acknowledgements}

We would like to thank Prof. Hitoshi Kanoh for several contributions to this manuscript. This research did not receive any specific grant from funding agencies in the public, commercial, or not-for-profit sectors.

\section{References}

Ali, M. and Pant, M. (2011). Improving the performance of differential evolution algorithm using cauchy mutation. Soft Computing, 15: 991-1007.

Anagnostopoulos, K. and Mamanis, G. (2011a). The meanvariance cardinality constrained portfolio optimization problem: An experimental evaluation of five multiobjective evolutionary algorithms. Expert Systems with Applications, 38: 14208-14217, doi:10.1016/J.ESWA.2011.04.233.

Anagnostopoulos, K. P. and Mamanis, G. (2011b). Multiobjective evolutionary algorithms for complex portfolio optimization problems. Computational Management Science, 8: 259-279, doi:10.1007/s10287-009-0113-8.

Arnone, S., Andrea Loraschi and Andrea Tettamanzi (1993). A Genetic Approach to Portfolio Selection. Neural Network World, 3: 597-604.

Aydogdu, I., Akin, A. and Saka, M. (2016). Design optimization of real world steel space frames using artificial bee colony algorithm with Levy flight distribution. Advances in Engineering Software, 92: 1-14, doi:10.1016/J. ADVENGSOFT.2015.10.013.

Bienstock, D. (1996). Computational study of a family of mixed-integer quadratic programming problems. Mathematical Programming, 74: 121-140, doi:10.1007/BF02592208.

Branke, J., Scheckenbach, B., Stein, M., Deb, K. and Schmeck, H. (2009). Portfolio optimization with an envelope-based multi-objective evolutionary algorithm. European Journal of Operational Research, 199: 684-693, doi: 10.1016/J.EJOR.2008.01.054.

Chang, T.-J., Meade, N., Beasley, J. and Sharaiha, Y. (2000). Heuristics for cardinality constrained portfolio optimisation. Computers $\&$ Operations Research, 27: 1271-1302, doi:10.1016/S0305-0548(99)00074-X.

Choi, T. J., Ahn, C. W. and An, J. (2013). An adaptive cauchy differential evolution algorithm for global numerical optimization. The Scientific World Journal, 2013.

Coello Coello, C. A. and Reyes Sierra, M. (2004). A Study of the Parallelization of a Coevolutionary Multi-objective Evolutionary Algorithm, Springer, Berlin, Heidelberg, pp. 688-697, doi:10.1007/978-3-540-24694-7_71. 
Deb, K. (2001). Multi-objective optimization using evolutionary algorithms, John Wiley \& Sons, ISBN 9780471873396.

Deb, K., Pratap, A., Agarwal, S. and Meyarivan, T. (2002). A fast and elitist multiobjective genetic algorithm: NSGA-II. IEEE Transactions on Evolutionary Computation, 6: 182-197, doi:10.1109/4235.996017.

Duran, F. C., Cotta, C. and Fernández, A. J. (2009). Evolutionary Optimization for Multiobjective Portfolio Selection under Markowitz's Model with Application to the Caracas Stock Exchange, Springer, Berlin, Heidelberg, pp. 489509, doi:10.1007/978-3-642-00267-0_18.

El-Bizri, S. and Mansour, N. (2017). Metaheuristics for Portfolio Optimization, Springer, Cham, pp. 77-84, doi:10.1007/978-3-319-61833-3_9.

Ertenlice, O. and Kalayci, C. B. (2018). A survey of swarm intelligence for portfolio optimization: Algorithms and applications. Swarm and Evolutionary Computation, 39: 36-52, doi:10.1016/J.SWEVO.2018.01.009.

Faezy Razi, F. and Shadloo, N. (2016). Portfolio selection using hybrid algorithm of data envelopment analysis based on Kohonen neural network and Cuckoo algorithm. Journal of Information and Optimization Sciences, 37: 549-567, doi:10.1080/02522667.2015.1103483.

Hakl, H. and Uuz, H. (2014). A novel particle swarm optimization algorithm with Levy flight. Applied Soft Computing, 23: 333-345, doi:10.1016/J.ASOC. 2014.06.034.

Hui Li and Qingfu Zhang (2009). Multiobjective Optimization Problems With Complicated Pareto Sets, MOEA/D and NSGA-II. IEEE Transactions on Evolutionary Computation, 13: 284-302, doi:10.1109/TEVC.2008.925798.

Jensi, R. and Jiji, G. W. (2016). An enhanced particle swarm optimization with levy flight for global optimization. Applied Soft Computing, 43: 248-261, doi:10.1016/J.ASOC.2016.02.018.

Jianli Zhou and Jun Li (2014). An improved multi-objective particle swarm optimization for constrained portfolio selection model, in 2014 11th International Conference on Service Systems and Service Management (ICSSSM), IEEE, ISBN 978-1-4799-3134-7, pp. 1-5, doi:10.1109/ICSSSM.2014.6874155.

Kamaruzaman, A. F., Zain, A. M., Yusuf, S. M. and Udin, A. (2013). Levy Flight Algorithm for Optimization Problems - A Literature Review. Applied Mechanics and Materials, 421: 496-501, doi:10.4028/www.scientific. net/AMM.421.496.

Ke, L., Zhang, Q. and Battiti, R. (2013). MOEA/D-ACO: A Multiobjective Evolutionary Algorithm Using Decomposition and AntColony. IEEE Transactions on Cybernetics, 43: 1845-1859, doi:10.1109/TSMCB.2012.2231860. 
Kumar, D. and Mishra, K. (2017). Portfolio optimization using novel co-variance guided Artificial Bee Colony algorithm. Swarm and Evolutionary Computation, 33: 119-130, doi:10.1016/J.SWEVO.2016.11.003.

Liagkouras, K. and Metaxiotis, K. (2014). A new Probe Guided Mutation operator and its application for solving the cardinality constrained portfolio optimization problem. Expert Systems with Applications, 41: 6274-6290, doi: 10.1016/J.ESWA.2014.03.051.

Liagkouras, K. and Metaxiotis, K. (2018). Handling the complexities of the multi-constrained portfolio optimization problem with the support of a novel MOEA. Journal of the Operational Research Society, 69: 1609-1627, doi: 10.1057/s41274-017-0209-4.

Liang, J. J. and Qu, B. Y. (2013). Large-scale portfolio optimization using multiobjective dynamic mutli-swarm particle swarm optimizer, in 2013 IEEE Symposium on Swarm Intelligence (SIS), IEEE, ISBN 978-1-4673-6004-3, pp. 1-6, doi:10.1109/SIS.2013.6615152.

Ma, W., Sun, Z., Li, J., Song, M., Lang, X. and Le, C. (2015). An Artificial Bee Colony Algorithm Guided by Lévy Flights Disturbance Strategy for Global Optimization, Springer, Cham, pp. 493-503, doi:10.1007/978-3-319-13707-0_ 54.

Mantegna, R. N. and Stanley, H. E. (1994). Stochastic Process with Ultraslow Convergence to a Gaussian: The Truncated Lévy Flight. Physical Review Letters, 73: 2946-2949, doi:10.1103/PhysRevLett.73.2946.

Markowitz, H. (1952). PORTFOLIO SELECTION*. The Journal of Finance, 7: 77-91, doi:10.1111/j.1540-6261.1952.tb01525.x.

Meghwani, S. S. and Thakur, M. (2018). Multi-objective heuristic algorithms for practical portfolio optimization and rebalancing with transaction cost. Applied Soft Computing, 67: 865-894, doi:10.1016/J.ASOC.2017.09.025.

Mishra, S., Panda, G., Meher, S., Majhi, R. and Singh, M. (2011). Portfolio management assessment by four multiobjective optimization algorithm, in 2011 IEEE Recent Advances in Intelligent Computational Systems, IEEE, ISBN 978-1-4244-9478-1, pp. 326-331, doi:10.1109/RAICS.2011.6069328.

Mishra, S. K., Meher, S., Panda, G. and Panda, A. (2009a). Comparative performance evaluation of multiobjective optimization algorithms for portfolio management, in 2009 World Congress on Nature 83 Biologically Inspired Computing (NaBIC), IEEE, ISBN 978-1-4244-5053-4, pp. 1338-1342, doi: 10.1109/NABIC.2009.5393739.

Mishra, S. K., Panda, G. and Majhi, R. (2014a). A comparative performance assessment of a set of multiobjective algorithms for constrained portfolio assets selection. Swarm and Evolutionary Computation, 16: 38-51, doi: 10.1016/J.SWEVO.2014.01.001. 
Mishra, S. K., Panda, G. and Majhi, R. (2014b). Constrained portfolio asset selection using multiobjective bacteria foraging optimization. Operational Research, 14: 113-145, doi:10.1007/s12351-013-0138-1.

Mishra, S. K., Panda, G. and Meher, S. (2009b). Multi-objective particle swarm optimization approach to portfolio optimization, in 2009 World Congress on Nature $\&$ Biologically Inspired Computing (NaBIC), IEEE, ISBN 978-1-42445053-4, pp. 1612-1615, doi:10.1109/NABIC.2009.5393659.

Orito, Y., Hanada, Y., Shibata, S. and Yamamoto, H. (2013). A New Population Initialization Approach Based on Bordered Hessian for Portfolio Optimization Problems, in 2013 IEEE International Conference on Systems, Man, and Cybernetics, IEEE, ISBN 978-1-4799-0652-9, pp. 1341-1346, doi: 10.1109/SMC.2013.232.

Qingfu Zhang and Hui Li (2007). MOEA/D: A Multiobjective Evolutionary Algorithm Based on Decomposition. IEEE Transactions on Evolutionary Computation, 11: 712-731, doi:10.1109/TEVC.2007.892759.

Shadkam, E., Delavari, R., Memariani, F. and Poursaleh, M. (2015). Portfolio selection by the means of cuckoo optimization algorithm. doi:10.5121/ijcsa. 2015.5304 .

Skolpadungket, P., Dahal, K. and Harnpornchai, N. (2007). Portfolio optimization using multi-obj ective genetic algorithms, in 2007 IEEE Congress on Evolutionary Computation, IEEE, ISBN 978-1-4244-1339-3, pp. 516-523, doi:10.1109/CEC.2007.4424514.

Tanabe, R. and Ishibuchi, H. (2019). Review and analysis of three components of the differential evolution mutation operator in MOEA/D-DE. Soft Computing: 1-15, doi:10.1007/s00500-019-03842-6.

Viswanathan, G., Raposo, E. and da Luz, M. (2008). Lévy flights and superdiffusion in the context of biological encounters and random searches. Physics of Life Reviews, 5: 133-150, doi:10.1016/J.PLREV.2008.03.002.

Wei Peng and Zhang, Q. (2008). A decomposition-based multi-objective Particle Swarm Optimization algorithm for continuous optimization problems, in 2008 IEEE International Conference on Granular Computing, IEEE, ISBN 978-14244-2512-9, pp. 534-537, doi:10.1109/GRC.2008.4664724.

Yang, X.-S. and Suash Deb (2009). Cuckoo Search via Lévy flights, in 2009 World Congress on Nature 85 Biologically Inspired Computing (NaBIC), IEEE, ISBN 978-1-4244-5053-4, pp. 210-214, doi:10.1109/NABIC.2009. 5393690.

Zhang, H., Zhao, Y., Wang, F., Zhang, A., Yang, P. and Shen, X. (2018). A new evolutionary algorithm based on MOEA/D for portfolio optimization, in 2018 Tenth International Conference on Advanced Computational Intelligence 
(ICACI), IEEE, ISBN 978-1-5386-4362-4, pp. 831-836, doi:10.1109/ICACI. 2018.8377569 .

Zhang, J. and Sanderson, A. C. (2009). Jade: adaptive differential evolution with optional external archive. IEEE Transactions on evolutionary computation, 13: 945-958.

Zhang, Q., Li, H., Maringer, D. and Tsang, E. (2010). MOEA/D with NBIstyle Tchebycheff approach for portfolio management, in IEEE Congress on Evolutionary Computation, IEEE, ISBN 978-1-4244-6909-3, pp. 1-8, doi:10. 1109/CEC.2010.5586185.

Zhang, R., Jiang, X. and Li, R. (2019). Improved decomposition-based multiobjective cuckoo search algorithm for spectrum allocation in cognitive vehicular network. Physical Communication, 34: 301-309, doi:10.1016/J. PHYCOM.2018.06.003.

Zhou, Z., Liu, X., Xiao, H., Wu, S. and Liu, Y. (2018). A DEA-based MOEA/D algorithm for portfolio optimization. Cluster Computing: 1-10, doi:10.1007/ s10586-018-2316-7. 